\title{
Intracellular itinerary of internalised $\beta$-secretase, BACE1, and its potential impact on $\beta$-amyloid peptide biogenesis
}

\author{
Pei Zhi Cheryl Chia*, Wei Hong Toh, Robyn Sharples*, Isabelle Gasnereau*, Andrew F. Hill*\% and Paul \\ A. Gleeson* \\ *The Department of Biochemistry and Molecular Biology and Bio21 Molecular Science and Biotechnology \\ Institute, The University of Melbourne, Victoria 3010, and ${ }^{\%}$ The Mental Health Research Institute of Victoria, \\ Parkville, Victoria 3010, Australia
}

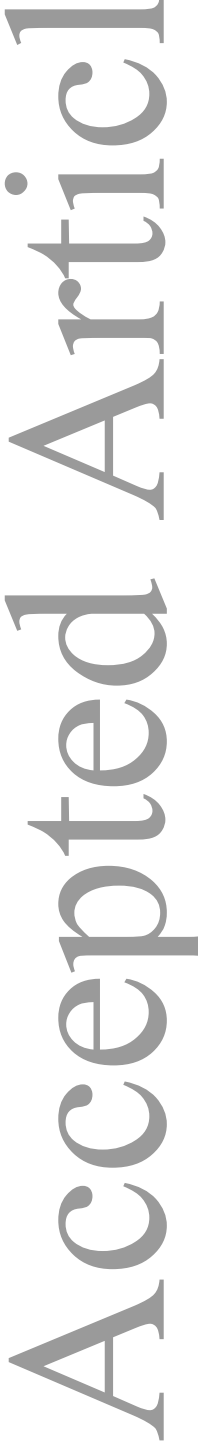
${ }^{1}$ Corresponding author: Prof. Paul Gleeson, Department of Biochemistry and Molecular Biology and Bio21 Molecular
Science and Biotechnology Institute, The University of Melbourne,Victoria 3010, Australia, Phone 61-3-8344-2354:Fax
61-3-9348-1428, E-mail: pgleeson@unimelb.edu.au

Abbreviations: $A \beta, \beta$-amyloid peptide; BACE1, beta site APP-cleaving enzyme: APP, amyloid precursor protein; TGN, trans-Golgi network

Synopsis

BACE1 cleavage of the amyloid precursor protein (APP) is the initial step in the formation of the amyloidogenic A $\beta$ peptide. This paper reports that cell surface BACE1 is internalised by the AP2/clathrin dependent pathway and traffics to early endosomes then recycling endosomes. In contrast, internalised wild-type APP traffics to late endosomes/lysosomes. A $\mathrm{BACE} / \mathrm{TGN} 38$ chimera that recycles via the TGN is more efficient in $\mathrm{A} \beta$ production than wild-type BACE1 indicating that the recycling itinerary of BACE1 influences $\mathrm{A} \beta$ biogenesis.

\begin{abstract}
:
$\beta$-secretase (BACE1) cleavage of the amyloid precursor protein (APP) represents the initial step in the formation of the Alzheimer's disease associated amyloidogenic A $\beta$ peptide. Substantive evidence indicates that APP processing by BACE1 is dependent on intracellular sorting of this enzyme. Nonetheless, knowledge of the intracellular trafficking pathway of internalised BACE1 remains in doubt. Here we show that cell surface BACE1 is rapidly internalised by the AP2/clathrin dependent pathway in transfected cells and traffics to early endosomes and Rab11-positive, juxtanuclear recycling endosomes, with very little transported to the TGN as has been previously suggested. Moreover, BACE1 is predominantly localised to the early and recycling endosome compartments in different cell types, including neuronal cells. In contrast, the majority of internalised wild-type APP traffics to late endosomes/lysosomes. To explore the relevance of the itinerary of BACE1 on APP processing, we generated a BACE1 chimera containing the cytoplasmic tail of TGN38 (BACE/TGN38), which cycles between the cell surface and TGN in an AP2-dependent manner. Wild-type BACE1 is less efficient in A $\beta$ production than the BACE/TGN38 chimera, highlighting the relevance of the itinerary of BACE1 on APP processing. Overall the data suggests that internalised BACE1 and APP diverge at early endosomes and that A $\beta$ biogenesis is regulated in part by the recycling itinerary of BACE1.
\end{abstract}

Key words: endosomal sorting, $\beta$-secretase, BACE1, recycling endosomes, trans-Golgi network, amyloid precursor protein, amyloid $\beta$ peptide.

This article has been accepted for publication and undergone full peer review but has not been through the copyediting, typesetting, pagination and proofreading process, which may lead to differences between this version and the Version of Record. Please cite this article as doi: $10.1111 /$ tra.12088 


\section{Introduction}

Senile plaques, consisting primarily of deposits of $\beta$ amyloid peptide $(A \beta)$, are a pathological hallmark of Alzheimer's disease (AD) (1). A $\beta$ is derived from sequential proteolysis of the amyloid precursor protein (APP) by $\beta$ - and $\gamma$-secretases (2). $\beta$-cleavage of APP is first carried out by the membrane-anchored aspartyl protease BACE1 (3-7) to generate a membrane-bound fragment (C99) that is subsequently cleaved by $\gamma$ secretase to yield $A \beta$. An alternative, non-amyloidogenic pathway involves the cleavage of APP by $\alpha$-secretase resulting in the release of the peptide $\mathrm{p} 3$ after $\gamma$-cleavage, a pathway that precludes $A \beta$ production (8).

The relative abundance of proteolytically-processed APP products, including $\mathrm{A} \beta$, is likely to reflect the intracellular localisation of APP and the different membrane secretases. The level of APP processing by BACE1 is dependent on the trafficking pathways of both BACE1 and APP, and also competition by $\alpha$-secretase, which cleaves APP to promote the protective or the nonamyloidogenic pathway. As $\alpha$-secretase is localised predominantly at the cell surface, it is likely that the majority of APP processing at the cell surface is along the non-amyloidogenic pathway $(9,10)$, whereas intracellular APP processing would predominantly involve the amyloidogenic pathway. As a member of the aspartyl protease family, BACE1 has an acidic $\mathrm{pH}$ optimum for activity and a number of intracellular location(s) for APP processing by BACE1 have been reported (11-13); the prevailing view is that $A \beta$ is generated mainly in the endosomes and TGN (14-18). As $\gamma$-secretase is present in multiple intracellular compartments (13), the processing of APP by BACE1 is the critical step in the biogenesis of $A \beta$. The potential relevance of endosomal sorting in neurological disease is highlighted by recent findings suggesting that defects in membrane trafficking events of the early endosomes, as a consequence of depletion of retromer components or the sortilin-related receptor SorLA for example, may be an underlying cause promoting enhanced APP processing and $\mathrm{A} \beta$ biogenesis in $\mathrm{AD}(19,20,21)$.

Defining the intracellular trafficking pathways of BACE1 and APP is clearly important to understand the cell biology of $A \beta$ production and to maximise opportunities for targeted inhibitors to BACE1. BACE1 is synthesised as a pro-protein in the endoplasmic reticulum (ER) where it is post-translationally modified by the addition of $\mathrm{N}$ glycans and the subsequent removal of the prodomain as it traverses the Golgi and is transported to the cell surface (22-24). BACE1 then recycles between the cell surface and endosomes $(11,13)$. However, the precise trafficking pathways of BACE1 and APP are not well defined. Recent studies have reported that BACE1 is internalised by either an AP2-mediated clathrin-dependent pathway (17) or alternatively a clathrin-independent Arf6dependent pathway (25). Moreover, some studies have indicated that internalised BACE1 may recycle via the early endosomes and $\operatorname{TGN}(26,27)$, which represents a defined endosomal retrograde transport pathway (28). Other studies have suggested that BACE1 is internalised and recycled from endosomes to the plasma membrane (PM) (24) or transported from early to late endosomes/lysosomes for degradation (29). Likewise, newly synthesised APP is delivered to the cell surface and then rapidly internalised. Many (30-32), but not all (33), studies suggest that the internalised APP is either degraded in lysosomes and/or recycled back to the cell surface, most likely from early or late endosomes, whereas other studies have suggested that APP is recycled to the TGN (18). Hence there is considerable uncertainty about the trafficking pathways of both BACE1 and APP and very few studies have analysed both membrane proteins within the same system.

The trafficking itineraries of transmembrane proteins are dependent on sorting signals in their cytoplasmic tail. Sorting motifs in the cytoplasmic tail of BACE1 have been identified (reviewed in (34)), however, the identification of internalisation motifs does not provide predictions on the precise intracellular itinerary of cargo. More detailed knowledge of the BACE1 trafficking pathway is required, information which may provide potential avenues for sequestering BACE1 from APP and reducing the yield of the amyloidogenic $A \beta$ peptide. Here we demonstrate that BACE1 recycles via the recycling endosomes, and not the TGN, in a variety of mammalian cells, including neurons. On the other hand internalised APP takes a different route and the majority is transported down the lysosomal pathway. Furthermore, we demonstrate that the itinerary of $\mathrm{BACE} 1$ is relevant to the regulation of $\mathrm{A} \beta$ production, as a BACE1 chimera that cycles via the TGN generates higher levels of $\mathrm{A} \beta$ levels compared with wild-type BACE1. Thus, we propose that the normal recycling of BACE1 through the recycling endosomes segregates BACE1 from APP and may be a factor that regulates the level of secreted $A \beta$ in normal cells.

\section{Results}

\section{Steady state distribution of BACE1 in cultured cells}

There remains considerable uncertainty about the precise intracellular trafficking routes of BACE1 (34). Previous studies have indicated that BACE1 is internalised into early endosomes and recycles to the plasma membrane (PM) via early/late endosomes or the TGN $(17,26,27$, 29). To accurately define the intracellular location and trafficking itinerary of BACE1 we have used a set of well-defined organelle-specific markers for the early and late endosomes, recycling endosomes and Golgi/TGN. Initially we examined the steady state distribution of BACE1 in HeLa cells transfected with a BACE1 construct. Full-length BACE1 was associated with punctate structures scattered throughout the cytoplasm and concentrated in the perinuclear region of the cell (Fig. 1A). Substantial overlap of BACE1 was detected with the early endosome marker, EEA1, whereas in contrast there was very little overlap with the late endosome/lysosomal marker, CD63 (Fig. S1). Dual staining with the Golgi stack marker, GM130, (Fig. 1A) or with the TGN marker, golgin-97 (not shown) showed some but not extensive overlap with BACE1 suggesting 
that the majority of the juxtanuclear localised BACE1 may be located in a compartment distinct from the Golgi. Notably, the recycling endosome is also located in the juxtanuclear region, however, the possibility that BACE1 could be localised to the recycling endosome has not been carefully investigated. Indeed, by staining for endogenous Rab11 as a marker of the recycling endosome, BACE1 co-localised extensively with the recycling endosome in transfected HeLa cells (Fig. 1B). The use of GFP-Rab11 as a marker for recycling endosomes also demonstrated considerable overlap with BACE1 (not shown), confirming the specificity of the endogenous Rab11 staining. Quantitation of the staining patterns revealed that, at steady state, BACE1 showed a $31.8 \%$ overlap with the early endosome marker, EEA1, $31.9 \%$ overlap with Rab11 and $4.4 \%$ overlap with the TGN marker, golgin-97, in HeLa cells (Fig. 1C).

To determine the relevance of these findings in $\mathrm{HeLa}$ cells, the steady-state distribution of BACE1 was then analysed in other cell lines including $\mathrm{CHO}$ cells, as this line allows excellent discrimination between recycling endosomes and other compartments and have been widely used to study APP processing events $(35,36)$, and SK-N-SH cells as this line represents a well-defined neuronal cell line relevant to AD (37). Significantly, very little overlap of BACE1 with the Golgi marker, GM130, was detected in either CHO or SK-N-SH cells (Fig. 1A) whereas extensive co-localisation of BACE1 and endogenous Rab11 was apparent in both $\mathrm{CHO}$ and SK-N-SH cells (Fig. 1B). These data clearly demonstrate that a substantial proportion of BACE1 is located at the recycling endosomes, and that the distribution of BACE1 is similar across different cell types, including a human neuronal cell line.

\section{Intracellular itinerary of BACE1}

To further define the intracellular itinerary of full-length BACE1, we tracked the transport of BACE1 from the $\mathrm{PM}$ to the Golgi apparatus using an antibody internalisation assay. HeLa cells were transfected with the wild-type BACE1 construct and incubated with antiBACE1 antibodies on ice. As expected, the antibodyBACE1 complexes were restricted to the cell surface at $4^{\circ} \mathrm{C}$ (Fig. 2A, $0 \mathrm{~min}$ ). Surface bound antibody-BACE1 complexes were then internalised at $37^{\circ} \mathrm{C}$ over a $60 \mathrm{~min}$ period. Antibody-BACE1 complexes were efficiently internalised; by 10-15 min the surface BACE1 had been internalised and was located in endosomal structures distributed in the cell periphery and throughout the cytoplasm (Fig. 2A, $15 \mathrm{~min}$ ). There was considerable overlap of BACE1 with the early endosome marker EEA1 at this early time point (Fig. 2B) as well as with endogenous Rab11 (Fig. 2E). After $60 \mathrm{~min}$ of internalisation, the majority of the internalised BACE1 remained located in punctate structures throughout the cytoplasm with a substantive co-localisation of internalised BACE1 with Rab11, particularly in the perinuclear region of the cell (Fig. 2C, E). Quantitative analysis showed an overlap of BACE1 with Rab11 of $\sim 30 \%$ at either 15 or $60 \mathrm{~min}$ of $37^{\circ} \mathrm{C}$ chase. In contrast, there was very little co-localisation detected with the TGN marker, golgin-97 (Fig. 2A), or the Golgi stack marker (GM130) (not shown), over the 60 min period (Fig. 2F).
The transferrin receptor (TfR) is known to recycle between the cell surface and the recycling endosomes (38). Given the intracellular transport of cell surface BACE1 to a Rab11-positive compartment, BACE1 may follow a similar intracellular trafficking route as that used by TfR. Therefore, we tracked BACE1 together with transferrin (Tf). Substantial co-localisation of $\mathrm{Tf}$ and BACE1 was observed at $15 \mathrm{~min}$ and $60 \mathrm{~min}$ after internalisation. At $60 \mathrm{~min}$ internalisation a significant level of staining was located in the perinuclear region of the cell (Fig. 2D), consistent with the location of recycling endosomes. Quantitative analyses showed that the overlap between the internalised Tf and BACE1 was $45.0 \pm 1.9 \%$ at $15 \mathrm{~min}$ and $42.1 \pm 1.15 \%$ at $60 \mathrm{~min}$ internalisation (Fig. 2G). Hence, BACE1 and TfR appear to have a similar intracellular trafficking route, further confirming that BACE1 localises to the recycling endosomes.

To determine whether Rab11 is required for the intracellular transport of BACE1 we examined the effect of the dominant-negative mutant Rab11S25N on the endosomal trafficking of BACE1. Rab11S25N has previously been shown to affect the transport of cargo sorted from the early /recycling endosomal compartments (39). HeLa cells were transfected with either GFPRab11wt or GFP-Rab11S25N together with BACE1 and an internalisation assay for BACE1 performed. We compared the transport of BACE1 through the EEA1positive early endosome compartment in Rab11wt and mutant Rab11S25N over-expressing cells. After $15 \mathrm{~min}$ internalisation, approximately $35 \%$ of BACE1 colocalised with EEA1 in both Rab11wt and Rab11S25N expressing cells (Fig. S2). Whereas the level of BACE1 in the EEA1-positive compartment then decreased in Rab11wt expressing cells over a subsequent period of 4575 min, no decrease was observed in the mutant GFPRab11S25N over-expressing cells (Fig. S2), indicating a block in transport from early endosomes and suggesting that a functional Rab11 is required for BACE1 intracellular trafficking.

Our previous studies have demonstrated that the membrane protein, TGN38, is transported directly from the early endosomes to the TGN (40). To determine the point of divergence of BACE1 and TGN38 along the endocytic pathway we investigated the trafficking of BACE1 and TGN38 simultaneously. Dual antibody uptake assays showed extensive co-localisation of BACE1 and TGN38 in punctate structures after $15 \mathrm{~min}$ internalisation (Fig. S3), which are likely to represent early endosomes based on the above time course study of BACE1. Internalisation for $45 \mathrm{~min}$ or $90 \mathrm{~min}$ resulted in segregation of BACE1 and TGN38, with internalised TGN38 localised predominantly with a TGN marker and BACE1 localised to independent peripheral punctate structures (Fig S3). These data suggest that the divergence of BACE1 and TGN38 most likely occurs from the early endosomes. Collectively these data indicate that BACE1 in internalised and is transported from early endosomes to recycling endosomes, similar to the trafficking of the TfR.

BACE1 internalisation is mediated by AP2 and clathrin 
There have been contradictory reports regarding the internalisation pathway of BACE1 from the PM to early endosomes. The di-leucine motif in the cytoplasmic tail of BACE1 has been suggested to facilitate clathrinmediated endocytosis (reviewed in (34)); recent reports have concluded that BACE1 is endocytosed predominantly either by an AP2-dependent (17) or an AP2-independent, Arf6-dependent (25) pathway. To assess the relevance of AP2 and clathrin in the endocytosis of BACE1, we have directly determined the machinery requirements for the internalisation of BACE1 from the cell surface. A characteristic of the clathrinmediated pathway is very rapid internalisation of cargo. To assess the impact of clathrin depletion on BACE1 distribution, the ubiquitous heavy chain isoform of clathrin (CHC17) was silenced in HeLa cells with a previously defined human $\mathrm{CHC} 17$ siRNA target sequence (41) followed by transfection with wild-type BACE1. Immunoblotting showed that the level of clathrin heavy chain was significantly reduced $(\sim 80 \%)$ in CHC17 siRNA transfected cells (Fig. 3A). As expected TfR accumulated on the surface of CHC17-depleted cells (Fig. 3B). The depletion of clathrin heavy chain also resulted in a dramatic reduction in the internalisation of BACE1 from the cell surface over a 15 min period (Fig. 3B). A similar finding was observed with AP2 $\mu 2$ depletion and AP2 $\alpha$-adaptin depletion, confirming the requirement for $\mathrm{AP} 2$ and clathrin in rapid internalisation of BACE1 (Fig. 3A, B).

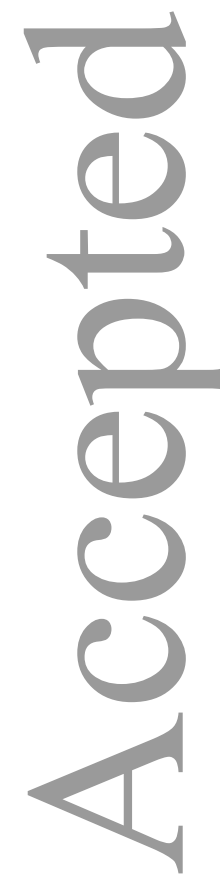

To quantitate the effect of clathrin depletion on BACE1 internalisation we analysed a transfected population of cells by FACS. BACE1 internalisation was carried out in suspension, where antibody was bound to cell surface BACE1 on ice, and cells incubated at $37{ }^{\circ} \mathrm{C}$ for $10 \mathrm{~min}$ before fixing and staining for surface antibody-BACE1 complexes with Alexa-conjugated anti-mouse IgG. Internalisation was assessed by the conversion of surface-BACE1 positive cells to surface BACE1negative cells. After $10 \mathrm{~min}$ internalisation at $37^{\circ} \mathrm{C}$, surface BACE1-positive cells were reduced from $26.8 \%$ of the transfected population to $18.8 \%$, a reduction of $30 \%$ and indicating rapid internalisation of a substantial quantity of surface BACE1 (Fig. 3C). Likewise, in cells treated with control siRNA there was a $\sim 30 \%$ reduction in the number of surface BACE1-positive cells after 10 min internalisation (Table 1). In contrast, cells depleted of $\mathrm{CHC} 17, \mu 2$ or $\alpha$-adaptin showed only a modest reduction of surface BACE1-antibody positive cells, namely $11.58 \%, 10.58 \%$ and $12.15 \%$, respectively (Table 1). We also analysed the impact of Arf6 depletion on BACE1 internalisation. Cells depleted of Arf6 ( $>90 \%$ depletion) rapidly internalised BACE1 and TfR from the cell surface by $15 \mathrm{~min}$ at $37^{\circ} \mathrm{C}$ as detected by confocal microscopy (Fig. 3A, B). In addition, flow cytometry showed no significant difference in the percentage of BACE1-positive cells after incubation for $10 \mathrm{~min}$ at $37^{\circ} \mathrm{C}$ between Arf6 siRNA-treated and control siRNA-treated cells (Table 1).

Extended periods of internalisation for 60 min or longer resulted in similar rates of conversion of surface BACE1positive cells to BACE1-negative cells regardless of the treatment (not shown), suggesting that bulk endocytosis may also contribute to the endocytosis of BACE1, albeit at a much slower rate than clathrin-mediated uptake.
We also verified using the FACS-based internalisation assay above that BACE1 endocytosis was dependent on the di-leucine motif in the cytoplasmic tail. As expected mutation of the di-leucine motif in the cytoplasmic tail of BACE1 (BACE1LL/AA) resulted in an enhanced level of BACE1 at the cell surface of the transfected cell population (not shown). Cell surface BACE1LL/AA was not readily internalised as demonstrated by no observed change in the percentage of cell surface BACE1-positive cells after $10 \mathrm{~min}$ internalisation at $37^{\circ} \mathrm{C}$ (Fig. 3C).

Given that the RNAi experiments did not completely block the internalisation of BACE1, which could be due to incomplete silencing, we also inhibited clathrin mediated endocytosis with the selective clathrin inhibitor, pitstop 2 (42) and assessed the internalisation of BACE1 (Fig. 4). To quantitate internalisation, cell surface proteins of intact cells were biotinylated with Sulfo-NHS-SS-biotin and the levels of biotinylated BACE1 assessed by immunoblotting of biotinylated complexes pulled out on NeutrAvidin beads. The selective release of the cell surface biotinylated molecules with the cell-impermeable reducing agent glutathione (GSH) allows the discrimination of cell surface BACE1 from internalised BACE1 (Fig. 4A). After $30 \mathrm{~min}$ or $60 \mathrm{~min}$ internalisation at $37^{\circ} \mathrm{C}$, a substantial proportion of biotinylated BACE1 was protected from glutathione release, indicating internalisation (Fig. 4B). At $30 \mathrm{~min}>50 \%$ of biotinylated BACE1 was protected from the cell impermeable glutathione, whereas at $60 \mathrm{~min}$ at $37^{\circ} \mathrm{C}$, following glutathione treatment at $30 \mathrm{~min}$ and $60 \mathrm{~min}$, $\sim 40 \%$ of biotinylated BACE1 was protected; the reduction between 30 and 60 min of biotinylated BACE1 suggests recycling of internalised BACE1 back to the cell surface. Incubation with pitstop 2 reduced the level of protected BACE1 and the majority of the biotinylated BACE1 $(\sim 80 \%)$ remained susceptible to cell surface release by glutathione (Fig $4 \mathrm{C}, \mathrm{D}$ ). On the other hand incubation with pitstop 2 followed by a $1 \mathrm{~h}$ washout on ice, and followed by an incubation at $37^{\circ} \mathrm{C}$ for $30 \mathrm{~min}$, resulted in $\sim 50 \%$ of biotinylated BACE1 being protected from glutathione reduction (Fig. 4C, D). Using antibodies to label cell surface BACE1, confocal microscopy confirmed that BACE1 was retained on the cell surface in pitstop 2-treated cells, whereas cell surface antibodyBACE1 complexes were internalised into EEA1-positive structures following washout of the inhibitor (Fig. 4E magnified image). These results show that the clathrin inhibitor, pitstop 2, blocks internalisation of the majority of surface BACE1 and that the effects of pitstop are reversible.

Therefore, collectively, these data confirm the requirement of the LL motif for internalisation of BACE1, and demonstrate that BACE1 is internalised predominantly via the AP2/clathrin-mediated pathway.

\section{Alteration of the intracellular distribution of BACE1}

The above data indicates that cell surface BACE1 is endocytosed by an AP2/clathrin dependent pathway and subsequently recycles via the recycling endosomes and not the TGN. To further discriminate between the recycling endosomes and the TGN, and to ascertain if there was functional consequence of re-directing BACE1 
trafficking to the TGN, we constructed a BACE1 mutant which is predicted to cycle via the TGN, by swapping the cytoplasmic tail of BACE1 with that from a membrane protein which undergoes retrograde transport from endosomes to the TGN. Specifically, we replaced the 23-residue cytoplasmic tail of BACE1 with the 34residue cytoplasmic tail of the membrane protein TGN38 (BACE/TGN38, Fig. 5A). TGN38 is known to recycle between the cell surface and the TGN via early endosomes, a trafficking route dependent on the cytoplasmic tail $(40,43)$. Both BACE1 and TGN38 are type 1 transmembrane proteins with $\mathrm{C}$-terminal cytoplasmic tails. Firstly, we assessed the internalisation pathway of the BACE/TGN38 chimera. BACE/TGN38 was internalised from the cell surface by the AP2/clathrin pathway as expected; silencing $\mathrm{CHC} 17$ or AP2 $\mu 2$ resulted in the inhibition of internalisation of cell surface BACE/TGN38 (not shown). Therefore the initial internalisation pathway of wild-type BACE1 and the BACE/TGN38 chimera are similar.

In contrast to wild-type BACE1, at steady state a considerable proportion of BACE/TGN38 was located at the Golgi of transiently transfected HeLa cells (Fig. 5B). Furthermore, antibody uptake assays showed that BACE/TGN38 was efficiently transported from the cell surface via endosomes to the Golgi over a $60 \mathrm{~min}$ period (Fig. 5C, D); notably at the $60 \mathrm{~min}$ time-point there was substantial $(\sim 50 \%)$ overlap with the Golgi marker, GM130 (Fig. 5C, D) indicating efficient retrograde transport of BACE/TGN38 to the Golgi.

These data demonstrate that the itinerary of the BACE/TGN38 chimera differs from wild-type BACE1, and that, in contrast to wt BACE1, the chimera is transported from endosomes to the TGN. Collectively, the data also provides further discrimination in the trafficking of cargo to either the recycling endosomes or the Golgi.

\section{Internalised APP predominantly traffics along the lysosomal pathway}

A number of studies have shown that APP is internalised from the PM to early endosomes and to the lysosomes for degradation (30-32). However, other studies suggest that APP can be recycled to the TGN (18) and moreover it has not been assessed whether any internalised APP may also be transported to the recycling endosomes. Therefore, we also tracked the transport of internalised APP from the PM. HeLa cells were transfected with wild-type APP and incubated with mouse monoclonal anti-APP antibodies on ice. The use of a mouse anti-APP antibody limited the use of organelle specific antibodies in these experiments and therefore the expression of the endosomal specific markers, Cherry-FYVE and GFPRab11wt, were used instead. Surface bound antibodyAPP complexes were then internalised at $37^{\circ} \mathrm{C}$ (Fig. 6A); after $15 \mathrm{~min}$ internalisation, antibody-APP complexes showed an intracellular punctate distribution (Fig. 6A) with an extensive co-localisation with the early endosome marker, Cherry-FYVE (Fig. 6B, D). Significantly very little increase in co-localisation with GFP-Rab11wt was detected after either $15 \mathrm{~min}$ or $30 \mathrm{~min}$ internalisation (Fig. 6A) or for up to $60 \mathrm{~min}$ (Fig. 6F). Likewise minimal co-localisation was detected between internalised APP and the TGN marker, p230/golgin245 (Fig. 6G); the latter was chosen as the TGN marker due to compatibility of the different antibodies used in the dual staining. Conversely, antibody-APP complexes colocalised extensively with Rab7-positive structures for extensive periods (Fig. 6C) with $\sim 30 \%$ of APP colocalising with GFP-Rab7(Q67L) after $60 \mathrm{~min}$ internalisation (Fig. 6E). The constitutive active from of $\mathrm{Rab} 7$ was used to demark the late endosomes as GFP-wt Rab7 shows only a low level of membrane staining with the majority of the fusion protein located in the cytosol.

One complication with the use of wild-type APP is that the tracking antibody recognizes the luminal domain of APP and therefore does not recognize the cleaved, membrane-associated, forms of APP. The intracellular sorting signals of APP are located in the cytoplasmic tail, and based on our recent work on endosomal sorting (44) it is also possible that the transmembrane domain may influence endosomal sorting events and trafficking. To ascertain whether APP has sorting signals in the cytoplasmic tail to direct this membrane cargo to the lysosomes, we have generated a cleavage-resistant APP chimeric protein containing the transmembrane domain and cytoplasmic tail of APP with the luminal reporter domain, CD8, a widely used reporter (45). Cell surface CD8/APP was labeled with anti-CD8 antibodies and complexes were internalised at $37^{\circ} \mathrm{C}$; after $30-60 \mathrm{~min}$, internalisation antibody-CD8/APP complexes showed co-localisation with both GFP-Rab7(Q67L) and the endogenous late endosome/lysosome marker LAMP1 marker (Fig. S4A, B). Quantitation showed there was a progressive increase in the co-localisation with GFPRab7(Q67L) and LAMP1 over a $60 \mathrm{~min}$ period (Fig. S4D, E), with only low levels of co-localisation with the TGN marker, p230 (Fig. S4C,F). Taken together these results confirm that the majority APP is internalised to late endosomes/lysosomes, suggesting that the intracellular transport pathways of BACE1 and APP differ.

\section{Effect of altered trafficking of BACE1 on APP processing}

To determine if there was a functional consequence of redirecting BACE1 trafficking from the recycling endosomes to the TGN, we compared the efficiency of $\mathrm{A} \beta$ biogenesis by wild-type BACE1 and the BACE/TGN38 chimera. For these experiments we employed a CHO cell line stably expressing APP695wt (35) as we have established that CHO-APP cell lines provide a sensitive system for the detection of $\mathrm{A} \beta$. CHOAPP stable clones expressing the BACE constructs were generated. Clones were selected which expressed very similar levels of BACE1 and BACE/TGN38; an immunoblot showed that BACE was present in the BACE1 and BACE/TGN38 CHO clones in a ratio of 1:1.25 respectively, based on normalisation with $\alpha$ tubulin (Fig. 8A). An immunoblot of a dilution series of the lysates showed a consistent ratio of $\mathrm{BACE}$ at various dilutions (not shown). The BACE/TGN38 chimera colocalised extensively with the Golgi marker, GM130, under steady-state conditions, whereas very little wildtype BACE1 co-localised with GM130 in the stable cell 
lines (Fig. 7A). The availability of Golgi markers for $\mathrm{CHO}$ cells is more restricted than HeLa cells, however, the extensive co-localisation of BACE/TGN38 with the Golgi stack marker GM130 clearly demonstrates Golgi localisation. Internalisation experiments were also performed to verify that the trafficking of BACE1 in these stable CHO-APP clones was similar to that of transiently transfected cells. As only low levels of surface expression were present in these stable clones, we incubated the $\mathrm{CHO}$ clones with anti-BACE1 antibody at $37^{\circ} \mathrm{C}$ to allow a continuous uptake of BACE1 from the cell surface. After $2 \mathrm{~h}$ internalisation, there were substantial levels of antibody-BACE/TGN38 co-localised with GM130, whereas very little internalised antibodywild-type BACE1 was detected in the Golgi region (Fig. 7B). Quantitation revealed a 2.3-fold higher level of internalised BACE/TGN38 at the Golgi compared with wild-type BACE1 (Fig. 7C). Therefore, the stable CHOAPP clones expressing the BACE constructs behaved in a similar fashion to the transiently transfected cells.

To determine the levels of $\mathrm{A} \beta$ production in the BACE1 stable CHO-APP lines, we analysed the secreted products for the presence of $A \beta$. The level of the secreted product of $\alpha$-secretase $(\operatorname{sAPP} \alpha)$ was also determined as a measure of overall secretion. Whereas similar levels of sAPP $\alpha$ was detected from BACE1 and BACE/TGN38 CHO-APP cells, there was a 3-fold higher level of $A \beta$ in the supernatants from the BACE/TGN38 CHO-APP cells compared with wt BACE1 CHO-APP cells (Fig. 8). The levels of $A \beta$ in these experiments were normalised for the level of BACE1 protein in each clone (Fig. 8A). A 3 -fold difference in $\mathrm{A} \beta$ production between the $\mathrm{CHO}$ clones was very reproducible and observed in four independent experiments (average of four experiments was 2.8-fold) with two independent clones of the constructs (Fig. 8C). Taken together, these data demonstrate that the precise intracellular trafficking pathways of BACE1 influence the yield of $A \beta$ generated and moreover show that recycling of BACE1 through the recycling endosomes reduces the yield of $A \beta$ compared with recycling via the TGN.

\section{Discussion}

The aggregation of $A \beta$ to form toxic oligomers and amyloid plaques is considered to be central to the pathogenesis of Alzheimer's disease, and the cleavage of APP by BACE1 is the initial step in the generation of A $\beta$ peptide (46). Substantive evidence indicates that the processing of APP by BACE1 is regulated by the intracellular sorting and trafficking of the enzyme, hence an understanding of membrane transport of BACE1 is of critical importance for the development of therapeutics to treat $\mathrm{AD}$. BACE1 recycles between the plasma membrane and a perinuclear compartment, previously considered to be the TGN $(26,27)$. The identity of this perinuclear compartment is highly relevant to the appreciation of potential major sites of APP processing. Our study has revealed that BACE1 is internalised by AP2/clathrin to early endosomes and then traffics from the early endosomes to the juxtanuclear recycling endosome (in both non-neuronal and neuronal cell lines), and not to the TGN/Golgi as previously thought. In contrast APP is internalised and transported predominantly along the endosomal/ lysosomal pathway. Our work has also revealed that the trafficking route of BACE1 is pertinent to APP processing and A $\beta$ generation. A BACE/TGN38 chimera, which is efficiently transported to the TGN by virtue of a defined TGN-retrieval motif in the TGN38 cytoplasmic tail (47), generates $A \beta$ levels considerably higher than wild-type BACE1. Given our findings, and the comparative itineraries of APP and BACE1 in transfected cells, we propose that internalised BACE1 and APP diverge at the early endosomes and that the transport of BACE1 to the recycling endosomes may be an important factor in regulating $A \beta$ production.

The internalisation of BACE1 from the cell surface has been attributed to a di-leucine motif $(17,24-26)$. The dileucine motif in the cytoplasmic tail of BACE1 is part of a more complex motif known as the acidic cluster-dileucine motif (DXXLL), composed of DISLL residues, $(24,26)$. Mutation of the leucines to alanines was previously shown to decrease internalisation of BACE1 $(24,48)$, thus implicating the DISLL sequence as an internalisation motif. Here we have confirmed the importance of the LL residues on internalisation of BACE1 and demonstrated that rapid internalisation is mediated by AP2 and clathrin endocytosis as silencing clathrin heavy chain, AP2 $\mu 2$ or AP2 $\alpha$-adaptin resulted in the inhibition of internalisation of BACE1. The effect on BACE1 internalisation by inhibition of clathrinmediated endocytosis with the small molecule inhibitor, pitstop 2, is also consistent with this conclusion, although the specificity of pitstop 2 for clathrin-mediated endocytosis has very recently been questioned (49). While this manuscript was in preparation another report was published which also demonstrated that endocytosis of BACE1 is mediated by AP2 and furthermore showed that the DDISLL sequence fits the consensus AP2 binding motif (17). Structural studies have recently revealed an interaction between the acidic cluster dileucine motifs with the hydrophobic pockets on the $\sigma 2$ subunit of AP2 (50), providing a molecular basis for clathrin-mediated endocytosis of BACE1. Another recent report had suggested that BACE1 endocytosis was independent of clathrin and AP2 but rather dependent on Arf6 (25). We were unable to demonstrate that Arf6 silencing had any effect on the rapid internalisation of BACE1 but did result in a modest increase in the level of BACE1 accumulating in early endosomes (unpublished data), findings consistent with the known role of Arf6 in intracellular recycling (51). However, our findings do not exclude a role for Arf6 in the slow internalisation of BACE1 by non-clathrin pathways.

BACE1 has a long half-life and recycles between endosomes and the PM multiple times during its lifespan (24). The perinuclear recycling endosome, also known as the endocytic recycling compartment (ERC), was distinguished from other endosomes and the Golgi by the specific marker Rab11 and by the localisation of internalised TfR (52), and the exclusion of EEA1 and Golgi markers. Moreover, a role for Rab11 and recycling endosomes in BACE1 trafficking is supported by the finding that Rab11(S25N) perturbs intracellular transport of BACE1. Our findings suggest that BACE1 has a similar intracellular trafficking pathway as TfR to the recycling endosomes. The perinuclear recycling 
endosome is often centrally located, juxtaposed alongside the microtubule organising centre, and in close proximity to the Golgi $(53,54)$. The perinuclear recycling endosome is characterised by the presence of Rab11 and has a tubular morphology from which transport carriers destined for the cell surface are derived (reviewed in (38, 55)). The observation that BACE1 is internalised to early endosomes and then to the Rab11-positive compartment suggests that a substantial level of internalised BACE1 takes the slow recycling route via the recycling endosomes back to the PM, a suggestion compatible with a role of Arf6 in recycling. A 'fast recycling route' from the early endosomes back to the PM has also been documented for TfR (55), and it is possible that some $\mathrm{BACE} 1$ may also use the fast recycling route.

Our study used transfected cells to examine the intracellular distribution of BACE1 at steady state conditions and the intracellular itinerary after internalisation from the cell surface. It is possible that the level of exogenous BACE1 may influence its' intracellular trafficking itinerary. However, we believe this is unlikely for the following reasons: Firstly, BACE1 was not retained in the ER indicating newly synthesized BACE1 was folded efficiently and was transported out of the ER. Secondly, the majority of BACE1 in transfected cells was located in early endosomes and recycling endosomes and very little BACE1 was detected in late endosomes (CD63 marker) at steady state in transfected cells. Moreover cell surface BACE1 was efficiently transported to the recycling endosomes, a pathway considered to be signal dependent (56). If over expression was influencing trafficking then one would expect inefficient sorting in the early endosomes resulting in default delivery to the late endosome and lysosome. The observation that there is efficient sorting and transport of BACE1 to the recycling endosome in transiently transfected HeLa cells and stable $\mathrm{CHO}$ cells argues that the expression levels have not saturated the machinery for sorting. Other studies have also used exogenous expression of BACE1 to monitor internalisation as surface levels of endogenous BACE1 are very difficult to detect $(17,27,57)$.

In contrast to BACE1, APP is internalised from the PM to early endosomes and is transported to lysosomes for degradation (30-32). Our studies here have confirmed these findings and, furthermore have demonstrated that APP is not transported to the recycling endosomes. Use of a reporter construct CD8/APP allowed the intracellular itinerary of the cytoplasmic tail of APP to be dissected without the complication of intracellular processing events for full-length APP. CD8/APP was internalised also to the late endosomes/lysosomes, confirming that the trafficking signals of APP direct the bulk of this membrane protein to lysosomes, at least in transfected HeLa cells.

A large proportion of APP is found at early endosomes at steady state and indeed the bulk of $A \beta$ production is thought to occur within this compartment (34), consistent with the preference of the aspartyl protease activity of BACE1 for an acidic $\mathrm{pH}$. Evidence that the early endosome is a major site for $A \beta$ biogenesis is supported by recent findings that the endosomal coat complex, retromer, is involved in the trafficking of BACE1. Significantly, RNAi silencing of one of the retromer components, Vps35, results in elevated levels of $A \beta$ in cultured cells $(19,21)$. Retromer defects have also been detected in the brains of $\mathrm{AD}$ cases, notably the downregulation of $\mathrm{Vps} 35$ (19). In addition, analysis of brains of mice expressing reduced levels of retromer (VPS26+/-) has revealed elevated levels of $A \beta$ and associated hippocampal dysfunction (20). Recent studies have indicated that retromer may regulate multiple transport steps from the early endosome, rather than solely facilitating retrograde transport. For example, retromer has been shown to be required for recycling of the $\beta 2$-adrenergic receptor directly back to the cell surface from early endosomes (58), and for sorting and transport from the early endosome to the recycling endosomes in addition to the well established role in endosome-to-TGN transport $(40,59)$; hence the potential importance of retromer on BACE1 trafficking. Interestingly, SorLA, a receptor of the Vps10-domain family, binds APP and is itself sorted in a retromerdependent manner (60-62), and moreover perturbations in SorLA levels manifests changes in trafficking of APP and $A \beta$ production. Sortilin, another member of the Vps10 family, also influences the endosomal trafficking of APP (63). These findings highlight the potential relevance of endosomal sorting and cargo receptors in BACE1 and APP trafficking and in neurodegenerative disease.

We assessed the impact of redirecting BACE1 via the TGN rather than the recycling endosomes. One advantage of directly manipulating the trafficking of BACE1, compared with the silencing of endosomal machinery components, is that the normal trafficking of APP remains unaffected. Redirecting BACE1 via the TGN rather than recycling endosomes resulted in a $\sim 3-$ fold increase in $A \beta$ production. Previous studies have shown that $A \beta$ production can occur in the secretory pathway $(64,65)$, and the enhanced production of $A \beta$ by BACE/TGN38 is likely to result from the TGN as a potential site for APP cleavage, in addition to early endosomes. The TGN has an acidic $\mathrm{pH}$ which is favourable for BACE1 activity, and recycling of BACE/TGN38 via the TGN will expose newly synthesised APP to high levels of BACE1 activity. Hence the enhanced production of $A \beta$ may result from BACE1 processing of newly synthesised APP arriving in the TGN. We did not detect any difference in the ratio of $A \beta 1-40 / 42$ products between wild-type BACE1 and BACE/TGN38 (unpublished data). In addition to Asp1 $\beta$-site cleavage to generate $A \beta 1-40 / 42$, BACE1 can also cleave at Glu11 ( $\beta$ '-site cleavage) which results in truncated $A \beta 11-40 / 42$ products. Previous reports have indicated that there may be enhanced APP $\beta$ 'site cleavage by BACE1 in the TGN compared with other locations (66), although the physiological relevance of these truncated $A \beta$ peptides remains unclear. Further work is clearly required to define the pathway for $A \beta$ production by the BACE/TGN38 chimera. Nonetheless, our finding of a 3-fold increase in $\mathrm{A} \beta 1-40 / 42$ production by BACE/TGN38 construct compared with wild-type BACE1 is likely to represent a physiologically significant difference in $A \beta$ production. Downregulation of the retromer component $\mathrm{Vps} 26$ results in 2-3 fold elevated levels of $A \beta$ and associated hippocampal dysfunction (67), illustrating the significance of a 3-fold difference with regards to in vivo cytotoxicity. 
In summary, the individual trafficking itineraries of APP and BACE1 are critical for the processing of APP along the amyloidogenic pathway resulting in $A \beta$ generation. We have demonstrated that cell surface APP and BACE1 have distinct trafficking itineraries. Importantly, we have demonstrated that BACE1 is transported predominantly to the recycling endosome and not the TGN as previously proposed, whereas APP is transported to late endosomes/lysosomes. We propose that internalised BACE1 and APP are segregated at the early endosomes by independent sorting events, and that BACE1 is predominantly transported to the recycling endosomes for transport back to the PM (Fig. 9). Through the segregation of BACE1 at the early endosome for recycling back to the cell surface via the recycling endosomes, internalised BACE1 is prevented from reaching the TGN. Thus the normal trafficking of BACE1 may be protective against excessive $A \beta$ production. These findings have important implications for the development of therapeutics, and could provide a novel approach to inhibit $A \beta$ production by interfering with BACE1 recycling.

\section{Materials and Methods}

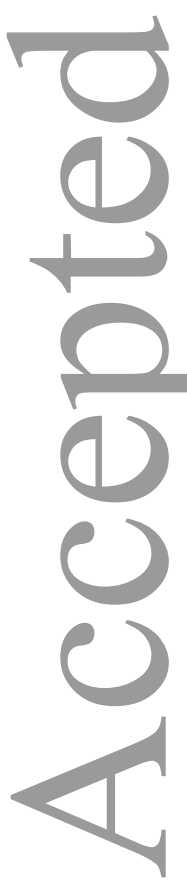

\section{Plasmids, antibodies and reagents}

pCDNA4/TO BACE1 was a gift from Michael Cater, Mental Health Research Institute, Victoria, Australia. GFP-Rab11wt, GFP-Rab11(S25N) and GFPRab7(Q67L) are N-terminal fusion constructs with GFP, as described (68). TGN38-CFP encodes a C-terminal fusion protein with the fluorescent CFP (69). mCherryFYVE $_{\text {EEA1 }}$ was generated by subcloning the region encoding the FYVE domain of EEA1 from GFPFYVE $_{\text {EEA1 }}$ (70) into the BgII and EcoRI sites of the mCherry-N1 vector (gift from Dr Roger Tsien UCSD, CA, USA). Mouse monoclonal anti- $\beta$ amyloid precursor protein was from Invitrogen (Camarillo, CA, USA). The full length APP cDNA in the pIRESpuro2 expression vector (Clontech Laboratories Inc., Mountain View, CA, USA) has been described (71). Mouse antibodies to clathrin heavy chain (clone 23), Rab11 (clone 47), EEA1 (clone 14), GM130 (clone 35) and TGN38 (clone 2/TGN38) were purchased from BD Bioscience (NSW, Australia). Mouse monoclonal antibodies to human CD63 (clone mx-49.129.5) was from Santa Cruz. Mouse monoclonal antibodies to golgin-97 (A-21270) were purchased from Life Technologies (NY, USA). Mouse monoclonal antibodies specific for A $35-8$ (W02) have been described (72). Mouse monoclonal antibodies to AP2 $\alpha$-adaptin (clone 100/2) and Arf6 (clone 3A-1) were from Sigma Aldrich (USA) and Santa Cruz Biotechnology, Inc (CA, USA) respectively. Mouse monoclonal antibodies to human CD8a (clone PA-T8) were from eBioscience (CA, USA). Affinity purified rabbit polyclonal anti-BACE1 (EE-17) was purchased from Sigma Aldrich (USA). Rabbit polyclonal antibodies to the $\mu 2$ subunit of AP2 and LAMP1 were purchased from Epitomics Inc. (CA, USA) and Abcam (Cambridge, UK) respectively. Human autoantibodies to p230 have been described previously (73).

Conjugates used for immunofluorescence were goat antirabbit IgG-Alexa Fluor 568, goat anti-rabbit IgG Alexa
Fluor 488, goat anti-mouse IgG-Alexa Fluor 488, goat anti-mouse IgG-Alexa Fluor 647, goat anti-human IgG Alexa Fluor 647 and goat anti-human IgG Alexa Fluor 568 from Molecular Probes (Invitrogen, Carlsbad, California, USA). Horseradish peroxidise-conjugated sheep anti-rabbit Ig and anti-mouse Ig were from DAKO Corporation (Carpinteria, California, USA). Can Get Signal Immunoreaction Enhancer Solution was purchased from Toyobo Life Science Department (Osaka, Japan).

\section{Generation of BACE/TGN38 and CD8/APP chimeric constructs}

A unique AgeI site was introduced at the junction of the transmembrane and cytoplasmic domains in the nucleotide sequence of wild-type BACE1 using the sitedirected mutagenesis using the primers 5, CACTCTGCCTCATGGTGTGTACCGG TCCGCTCGAGTCTAGAGGGCC 3 , and 5' GGCCCTCTAGACTCGAGCGGACC

GGTACACACCATGAGGCAGAGTG 3 ' to produce pCDNA4/TO BACE1 AgeI. The cytoplasmic tail sequence of rat TGN38 was amplified with flanking AgeI restriction sites by PCR using the primers 5, GGGGGACCGGTCACAACA AACCGA 3' and 5, CCCCCACCGGTTCAAAGCTTTAGGTT 3'. The amplified product was purified and digested with AgeI before ligation into AgeI-digested pCDNA4/TO BACE1 AgeI. The pCDNA4/TO BACE1LL/AA mutant was obtained using the primers 5, TTTGCTGATGACATCTCCGCTGCTAAGTGATGAC $\begin{array}{lll} & \\ \text { TCGAGTCT } & \text { and }\end{array}$ AGACTCGAGTCATCACTTAGCAGCGGAGATGTC ATCAGCAAA

3 ' by site-directed mutagenesis, using pCDNA4/TO BACE1 as a template.

To generate the CD8-APP construct, the transmembrane and cytoplasmic domains of APP was amplified with flanking 5'HindIII and 3' Xba sites by PCR using the primers CCCAAGCTTGGTGCAATCATTGGACTCAT3' and 5'TGCTCTAGACTAGTTCTGCATCTGCTCAA3'.

The CD8 luminal domain was isolated from the CD8M6PR vector construct (74) by PCR and including flanking 5' XhoI and 3' HindIII sites. The CD8 and APP fragments were ligated into XhoI- and HindIII digested pCI-Neo.

\section{Cell culture and transient transfections}

$\mathrm{HeLa}$ cells and human neuronal SK-N-SH cells were maintained as semi-confluent monolayers in DMEM supplemented with $10 \%(\mathrm{v} / \mathrm{v})$ fetal calf serum (FCS), 2 $\mathrm{mM}$ L-glutamine, 100 units $/ \mu 1$ penicillin and $0.1 \%(\mathrm{w} / \mathrm{v})$ streptomycin (C-DMEM). Chinese Hamster Ovary (CHO) cells were grown in RPMI media supplemented with $10 \%(\mathrm{v} / \mathrm{v})$ fetal calf serum (FCS), $2 \mathrm{mM} \mathrm{L-}$ glutamine, 100 units $/ \mu \mathrm{l}$ penicillin and $0.1 \%(\mathrm{w} / \mathrm{v})$ streptomycin (C-RPMI). Cells were maintained in a humidified $10 \% \mathrm{CO}_{2}$ atmosphere at $37^{\circ} \mathrm{C}$. For transient transfections, HeLa cells were seeded as monolayers and transfected using Fugene 6 (Roche Diagnostic, Basel, Switzerland) and for CHO and SK-N-SH cells, cells were transfected with Lipofectamine 2000 (Invitrogen, Carlsbad, CA, USA) and Opti-MEM according to manufacturer's instructions. Transfections were carried out in C-DMEM or C-RPMI at $37^{\circ} \mathrm{C}, 10 \% \mathrm{CO}_{2}$ for $24 \mathrm{~h}$. 


\section{RNA interference}

The human $\mathrm{CHC} 17(1)$ specific siRNA duplex is as described in (41). The human $\mu 2(1), \alpha$-adaptin(1) and CHC17(2) specific siRNA duplexes are described by (75). siRNA duplexes for Arf6(1) (76), Arf6(2) (77), $\mu 2(2)$ (78) and $\alpha$-adaptin(2) (17) are as described. All above described siRNA target sequences were purchased from Sigma Proligos (Lismore, Australia).

\section{Generation of stable cell lines}

A CHO cell line stably expressing APP695WT (CHOAPP) (35) was maintained in C-RPMI with $7.5 \mu \mathrm{g} / \mathrm{ml}$ of puromycin (Sigma Aldrich). BACE1-CHO-APP and BACE/TGN38-CHO-APP cell lines were generated by transfecting the CHO-APP cell line with either wild-type BACE1 or BACE/TGN38 constructs respectively, using Lipofectamine 2000 (Invitrogen, Carlsbad, California, USA). Stably expressing cells were selected and maintained in C-RPMI medium with $7.5 \mu \mathrm{g} / \mathrm{ml}$ puromycin and $50 \mu \mathrm{g} / \mathrm{ml}$ zeomycin (Sigma Aldrich). Monoclonal cell lines were generated by limiting dilution.

\section{Indirect immunofluorescence}

Cells on coverslips were fixed with $4 \%$ paraformaldehyde for $15 \mathrm{~min}$, followed by quenching in $50 \mathrm{mM} \mathrm{NH}_{4} \mathrm{Cl} / \mathrm{PBS}$ for $10 \mathrm{~min}$. Cells were permeabilised in $0.1 \%$ Triton $\mathrm{X}-100 / \mathrm{PBS}$ for 4 min and blocked in 5\% FCS/PBS for $20 \mathrm{~min}$ to reduce non-specific binding. Monolayers were incubated with primary and secondary conjugates as described (79) and confocal microscopy performed using a Leica TCS SP2 imaging system. For endogenous Rab11 staining, cells were fixed with $10 \%$ trichloroacetic acid in PBS for $15 \mathrm{~min}$, followed by quenching with $30 \mathrm{mM}$ glycine/PBS. Cells were then permeabilised and with $0.1 \%$ Triton X-100/PBS and blocked with 5\% FCS/PBS as described above. Monolayers were incubated with mouse anti-Rab11 antibodies diluted in Can Get Signal Solution A (Toyobo, Japan), followed by incubation in secondary conjugates diluted in blocking solution. Images were collected independently for multi-colour labelling.

\section{Internalisation assay}

Cells were transfected $24 \mathrm{hr}$ prior to the internalisation assay. Rabbit polyclonal BACE1 antibodies $(2 \mu \mathrm{g} / \mathrm{ml})$, APP antibodies $(10 \mu \mathrm{g} / \mathrm{ml})$ or CD 8 antibodies $(2.5 \mu \mathrm{g} / \mathrm{ml})$ were incubated with cells on ice for $30 \mathrm{~min}$, cells washed, and the BACE1 or APP antibody-bound complexes internalised for the indicated time period in serum-free media. For dual internalisation of BACE1 and TGN38, transfected cells were incubated with both rabbit anti-BACE1 $(2 \mu \mathrm{g} / \mathrm{ml})$ and mouse anti-rat TGN38 (1.25 $\mu \mathrm{g} / \mathrm{ml}$ ) in serum-free medium for $30 \mathrm{~min}$ as above. Cells were then fixed with $4 \%$ paraformaldehyde according to the fixation procedure and stained with fluorochromeconjugated secondary antibodies.

\section{Quantitation of immunofluorescence}

Quantitation of the co-localisation between internalised BACE1 and fluorescent organelle markers was performed using the plugin Organelle-Based Colocalisation (OBCOL) as described by Woodcroft et al. (80), on the ImageJ programme (NIH public domain software) for the indicated number of cells at each timepoint. The percentage of BACE1, BACE/TGN38 or
CD8/APP at different organelles was determined by taking the sum of overlapping pixels between BACE1 and respective markers, divided by the total number of BACE1 pixels within each cell. Data obtained from fluorescence intensity of Golgi-localised antibodyBACE1 or antibody-BACE/TGN38 complexes was expressed as the mean, +/- SEM and analysed by an unpaired, two-tailed, student t-test. A $p<0.05$ (*) was considered significant, $p<0.01(* *)$ highly significant and $p<0.001(* * *)$ very highly significant. The absence of a $p$ value indicates the differences were not significant.

\section{Immunoblotting}

For immunoblotting of cell lysates, cell extracts were dissolved in reducing sample buffer and samples resolved on a $4-12 \%$ NuPAGE gradient gel and immunoblotting was performed as described (74). Blots were imaged using the Gel Pro Analyzer program (MediaCybernetics, Bethesda, USA) and levels of protein normalised to the levels of cell associated tubulin.

\section{Cell surface biotinylation}

HeLa cells were transfected with BACE1 for 24 hours and cell surface biotinylation was performed as described (17). Briefly, cells were incubated in $1 \mathrm{mM}$ Sulfo-NHSSS-Biotin (Pierce, Rockford, IL, USA) in PBS for $1 \mathrm{~h}$ on ice. Unreacted ester was quenched in cold $50 \mathrm{mM}$ Tris$\mathrm{HCl}$ for $10 \mathrm{~min}$. Cells were then lysed in cell lysis buffer (50mM Tris- $\mathrm{HCl}, \mathrm{pH} 7.5,150 \mathrm{mM} \mathrm{NaCl}, 2$ mM EDTA, $1 \%(\mathrm{v} / \mathrm{v})$ Triton $\mathrm{X}-100$, containing protease inhibitors (Roche Applied Science, Indianopolis, IN, USA). For internalisations, cells were surface biotinylated as described, and then incubated at $37^{\circ} \mathrm{C}$ for $30 \mathrm{~min}$ or 60 min. Cells were then treated with cleavage buffer $(50$ $\mathrm{mM}$ glutathione (Sigma Aldrich), $90 \mathrm{mM} \mathrm{NaCl}, 1.25$ $\mathrm{mM} \mathrm{CaCl}_{2}, 1.25 \mathrm{mM} \mathrm{MgSO}_{4}, 0.2 \%$ BSA pH 8.6) for $1 \mathrm{~h}$ on ice, followed by treatment with $50 \mathrm{mM}$ iodoacetamide for $30 \mathrm{~min}$ to quench remaining glutathione. Cells were lysed in cell lysis buffer in the presence of $2.5 \mathrm{mM}$ iodoacetamide. For pitstop treatment, surface biotinylated cells were treated with $30 \mu \mathrm{M}$ pitstop 2 (Abcam, Cambridge, UK) in PBS for 15 min on ice prior to incubation at $37^{\circ} \mathrm{C}$ for $30 \mathrm{~min}$, with or without a $1 \mathrm{~h}$ washout with cold C-DMEM, followed by glutathione cleavage. Lysates were extracted with cell lysis buffer. All lysates were incubated with NeutrAvidin-agarose (Pierce) in a rotary shaker at $4^{\circ} \mathrm{C}$ for 2 hours. Beads were washed 3 times with cell lysis buffer and analysed by SDS-PAGE followed by immunoblotting with BACE1 antibody. Densitometry of bands was carried out using Image J.

\section{FACS analysis of BACE1 internalisation}

$\mathrm{HeLa}$ cells were transfected with BACE1 or BACE1LL/AA for $24 \mathrm{~h}$ and antibody-BACE1 uptake assay was carried out in suspension. For siRNA-treated cells, cells were first transfected with siRNA for $48 \mathrm{~h}$ followed by transfection with BACE1 for a further $24 \mathrm{~h}$, prior to the BACE uptake assay. Monolayers were harvested by trypsin digest at $37^{\circ} \mathrm{C}$ for $3 \mathrm{~min}$. Trypsin treatment had no effect on the levels of surface BACE1, as determined by comparison with EDTA harvested monolayers. After incubation at $37^{\circ} \mathrm{C}$, cells were fixed with 4\% PFA/PBS. Quenching and blocking was performed as described above, without permeabilisation. Cells were then stained with rabbit Alexa568-conjugated 
IgG and cells resuspended in FACS buffer $(2 \mathrm{mM}$ EDTA/PBS) for analysis on a Becton Dickinson LSRFortessa flow cytometer. Data was analysed with BD FACSDiva software (BD Biosciences).

\section{Analysis of secreted A $\beta$ by $\mathrm{CHO}$ cells}

$\mathrm{A} \beta$ blots of conditioned media from cell lines were carried out as described (35). Briefly, BACE APP CHO cells were seeded at $1.5 \times 10^{5}$ cells per well in a 12 well plate and grown to $90 \%$ confluency in C-RPMI supplemented with $50 \mu \mathrm{g} / \mathrm{mL}$ zeomycin and $7.5 \mathrm{ug} / \mathrm{mL}$ puromycin. The following day, selection media was removed and cells were washed twice with PBS. A 300 $\mu l$ aliquot of C-RPMI without antibiotics was added to each well and after $16 \mathrm{~h}$ incubation media from each well was removed for $A \beta$ analysis. Monolayers from corresponding wells were collected, cells lysed in reducing sample buffer and the samples analysis by immunoblotting to determine BACE expression levels. Conditioned media was centrifuged to pellet debris and $10 \mu \mathrm{l}$ of conditioned media added to $10 \mu \mathrm{l}$ of $2 \mathrm{x}$ reducing sample buffer and $15 \mu \mathrm{l}$ of the mixture was loaded per well of a $10 \%$ Tricine pre-cast gel for immunoblotting.

\section{Acknowledgements}

We thank Dr Jet Phey Lim for mCherry-FYVE $E_{\text {EEA1 }}$ construct. This work was supported by funding from the National Health and Medical Research Council of Australia. PZCC and WHT are supported by Melbourne International Graduate Scholarships and AFH is supported by an ARC Future Fellowship. The authors declare no conflict of interest.

\section{References}

1. Masters CL, Simms G, Weinman NA, Multhaup G, McDonald BL, Beyreuther K. Amyloid plaque core protein in Alzheimer disease and Down syndrome. Proc Natl Acad Sci U S A 1985;82(12):4245-4249.

2. Wilson CA, Doms RW, Lee VM. Intracellular APP processing and A beta production in Alzheimer disease. J Neuropathol Exp Neurol 1999;58(8):787794.

3. Hussain I, Powell D, Howlett DR, Tew DG, Meek TD, Chapman C, Gloger IS, Murphy KE, Southan CD, Ryan DM, Smith TS, Simmons DL, Walsh FS, Dingwall C, Christie G. Identification of a novel aspartic protease (Asp 2) as beta-secretase. Mol Cell Neurosci 1999;14(6):419-427.

4. Lin X, Koelsch G, Wu S, Downs D, Dashti A, Tang J. Human aspartic protease memapsin 2 cleaves the beta-secretase site of beta-amyloid precursor protein. Proc Natl Acad Sci U S A 2000;97(4):1456-1460.

5. Sinha S, Anderson JP, Barbour R, Basi GS, Caccavello R, Davis D, Doan M, Dovey HF, Frigon N, Hong J, Jacobson-Croak K, Jewett N, Keim P, Knops J, Lieberburg I, et al. Purification and cloning of amyloid precursor protein beta-secretase from human brain. Nature 1999;402(6761):537-540.

6. Vassar R, Bennett BD, Babu-Khan S, Kahn S, Mendiaz EA, Denis P, Teplow DB, Ross S, Amarante P, Loeloff R, Luo Y, Fisher S, Fuller J, Edenson S, Lile J, et al. Beta-secretase cleavage of Alzheimer's amyloid precursor protein by the transmembrane aspartic protease BACE. Science 1999;286(5440):735-741.

7. Yan R, Bienkowski MJ, Shuck ME, Miao H, Tory MC, Pauley AM, Brashier JR, Stratman NC, Mathews WR, Buhl AE, Carter DB, Tomasselli AG, Parodi LA, Heinrikson RL, Gurney ME. Membraneanchored aspartyl protease with Alzheimer's disease beta-secretase activity. Nature 1999;402(6761):533537.

8. Esch FS, Keim PS, Beattie EC, Blacher RW, Culwell AR, Oltersdorf T, McClure D, Ward PJ. Cleavage of amyloid beta peptide during constitutive processing of its precursor. Science 1990;248(4959):1122-1124.

9. Parvathy S, Hussain I, Karran EH, Turner AJ, Hooper NM. Cleavage of Alzheimer's amyloid precursor protein by alpha-secretase occurs at the surface of neuronal cells. Biochemistry 1999;38(30):9728-9734.

10. Sisodia SS. Beta-amyloid precursor protein cleavage by a membrane-bound protease. Proc Natl Acad Sci U S A 1992;89(13):6075-6079.

11. Cole SL, Vassar R. The Alzheimer's disease betasecretase enzyme, BACE1. Mol Neurodegener 2007;2:22.

12. Marks N, Berg MJ. BACE and gamma-secretase characterization and their sorting as therapeutic targets to reduce amyloidogenesis. Neurochem Res 2010;35(2):181-210.

13. Thinakaran G, Koo EH. Amyloid precursor protein trafficking, processing, and function. J Biol Chem 2008;283(44):29615-29619.

14. Huse JT, Doms RW. Neurotoxic traffic: uncovering the mechanics of amyloid production in Alzheimer's disease. Traffic 2001;2(2):75-81.

15. Koo EH, Squazzo SL. Evidence that production and release of amyloid beta-protein involves the endocytic pathway. J Biol Chem 1994;269(26):17386-17389.

16. Tienari PJ, Ida N, Ikonen E, Simons M, Weidemann A, Multhaup G, Masters CL, Dotti CG, Beyreuther K. Intracellular and secreted Alzheimer beta-amyloid species are generated by distinct mechanisms in cultured hippocampal neurons. Proc Natl Acad Sci U S A 1997;94(8):4125-4130.

17. Prabhu Y, Burgos PV, Schindler C, Farias GG, Magadan JG, Bonifacino JS. Adaptor protein 2mediated endocytosis of the beta-secretase BACE1 is dispensable for amyloid precursor protein processing. Molecular Biology of the Cell 2012;23(12):23392351.

18. Choy RW, Cheng Z, Schekman R. Amyloid precursor protein (APP) traffics from the cell surface via endosomes for amyloid beta (Abeta) production in the trans-Golgi network. Proceedings of the National Academy of Sciences of the United States of America 2012;109(30):E2077-2082.

19. Small SA, Kent K, Pierce A, Leung C, Kang MS, Okada H, Honig L, Vonsattel JP, Kim TW. Modelguided microarray implicates the retromer complex in Alzheimer's disease. Ann Neurol 2005;58(6):909919.

20. Muhammad A, Flores I, Zhang H, Yu R, Staniszewski A, Planel E, Herman M, Ho L, Kreber R, Honig LS, Ganetzky B, Duff K, Arancio O, Small SA. Retromer deficiency observed in Alzheimer's disease causes hippocampal dysfunction, 
neurodegeneration, and Abeta accumulation. Proc Natl Acad Sci U S A 2008;105(20):7327-7332.

21. Rogaeva E, Meng Y, Lee JH, Gu Y, Kawarai T, Zou F, Katayama T, Baldwin CT, Cheng R, Hasegawa $\mathrm{H}$, Chen F, Shibata N, Lunetta KL, Pardossi-Piquard R, Bohm C, et al. The neuronal sortilin-related receptor SORL1 is genetically associated with Alzheimer disease. Nat Genet 2007;39(2):168-177.

22. Capell A, Steiner H, Willem M, Kaiser H, Meyer C, Walter J, Lammich S, Multhaup G, Haass C Maturation and pro-peptide cleavage of betasecretase. J Biol Chem 2000;275(40):30849-30854.

23. Creemers JW, Ines Dominguez D, Plets E, Serneels L, Taylor NA, Multhaup G, Craessaerts K, Annaert W, De Strooper B. Processing of beta-secretase by furin and other members of the proprotein convertase family. J Biol Chem 2001;276(6):4211-4217.

24. Huse JT, Pijak DS, Leslie GJ, Lee VM, Doms RW. Maturation and endosomal targeting of beta-site amyloid precursor protein-cleaving enzyme. The Alzheimer's disease beta-secretase. J Biol Chem 2000;275(43):33729-33737.

25. Sannerud R, Declerck I, Peric A, Raemaekers T, Menendez G, Zhou L, Veerle B, Coen K, Munck S, De Strooper B, Schiavo G, Annaert W. ADP ribosylation factor 6 (ARF6) controls amyloid precursor protein (APP) processing by mediating the endosomal sorting of BACE1. Proceedings of the National Academy of Sciences of the United States of America 2011;108(34):E559-568.

26. He X, Li F, Chang WP, Tang J. GGA proteins mediate the recycling pathway of memapsin 2 (BACE). J Biol Chem 2005;280(12):11696-11703.

27. Wahle T, Prager K, Raffler N, Haass C, Famulok M, Walter J. GGA proteins regulate retrograde transport of BACE1 from endosomes to the trans-Golgi network. Mol Cell Neurosci 2005;29(3):453-461.

28. Lieu ZZ, Gleeson PA. Endosome-to-Golgi transport pathways in physiological processes. Histol Histopathol 2011;26(3):395-408.

29. Koh YH, von Arnim CA, Hyman BT, Tanzi RE, Tesco G. BACE is degraded via the lysosomal pathway. J Biol Chem 2005;280(37):32499-32504.

30. Koo EH, Squazzo SL, Selkoe DJ, Koo CH. Trafficking of cell-surface amyloid beta-protein precursor. I. Secretion, endocytosis and recycling as detected by labeled monoclonal antibody. J Cell Sci 1996;109 ( Pt 5):991-998.

31. Lorenzen A, Samosh J, Vandewark K, Anborgh PH, Seah C, Magalhaes AC, Cregan SP, Ferguson SS, Pasternak SH. Rapid and direct transport of cell surface APP to the lysosome defines a novel selective pathway. Mol Brain 2010;3:11.

32. Yamazaki T, Koo EH, Selkoe DJ. Trafficking of cellsurface amyloid beta-protein precursor. II. Endocytosis, recycling and lysosomal targeting detected by immunolocalization. J Cell Sci 1996;109 ( Pt 5):999-1008.

33. Vieira SI, Rebelo S, Esselmann H, Wiltfang J, Lah J, Lane R, Small SA, Gandy S, da Cruz ESEF, da Cruz ESOA. Retrieval of the Alzheimer's amyloid precursor protein from the endosome to the TGN is S655 phosphorylation state-dependent and retromermediated. Mol Neurodegener 2010;5:40.

34. Chia PZ, Gleeson PA. Intracellular trafficking of the beta-secretase and processing of amyloid precursor protein. IUBMB Life 2011;63(9):721-729.
35. Sharples RA, Vella LJ, Nisbet RM, Naylor R, Perez $\mathrm{K}$, Barnham KJ, Masters CL, Hill AF. Inhibition of gamma-secretase causes increased secretion of amyloid precursor protein C-terminal fragments in association with exosomes. FASEB J 2008;22(5):1469-1478.

36. Walsh DM, Klyubin I, Fadeeva JV, Cullen WK, Anwyl R, Wolfe MS, Rowan MJ, Selkoe DJ. Naturally secreted oligomers of amyloid beta protein potently inhibit hippocampal long-term potentiation in vivo. Nature 2002;416(6880):535-539.

37. Peng S, York JP, Zhang P. A transgenic approach for RNA interference-based genetic screening in mice. Proc Natl Acad Sci U S A 2006;103(7):2252-2256.

38. Maxfield FR, McGraw TE. Endocytic recycling. Nature reviews Molecular cell biology 2004;5(2):121-132

39. Wilcke M, Johannes L, Galli T, Mayau V, Goud B, Salamero J. Rab11 regulates the compartmentalization of early endosomes required for efficient transport from early endosomes to the trans-golgi network. J Cell Biol 2000;151(6):12071220.

40. Lieu ZZ, Gleeson PA. Identification of different itineraries and retromer components for endosometo-Golgi transport of TGN38 and Shiga toxin. Eur J Cell Biol 2010;89(5):379-393.

41. Huang F, Khvorova A, Marshall W, Sorkin A. Analysis of clathrin-mediated endocytosis of epidermal growth factor receptor by RNA interference. J Biol Chem 2004;279(16):1665716661.

42. von Kleist L, Stahlschmidt W, Bulut H, Gromova K, Puchkov D, Robertson MJ, MacGregor KA, Tomilin N, Pechstein A, Chau N, Chircop M, Sakoff J, von Kries JP, Saenger W, Krausslich HG, et al. Role of the clathrin terminal domain in regulating coated pit dynamics revealed by small molecule inhibition. Cell 2011;146(3):471-484.

43. Banting G, Ponnambalam S. TGN38 and its orthologues: Roles in post-TGN vesicle formation and maintenance of TGN morphology. Biochimica et Biophysica Acta - Molecular Cell Research 1997;1355(3):209-217.

44. Chia PZ, Gasnereau I, Lieu ZZ, Gleeson PA. Rab9dependent retrograde transport and endosomal sorting of the endopeptidase furin. Journal of Cell Science 2011;124(Pt 14):2401-2413.

45. Seaman MN. Identification of a novel conserved sorting motif required for retromer-mediated endosome-to-TGN retrieval. J Cell Sci 2007;120(Pt 14):2378-2389.

46. Tanzi RE, Bertram L. Twenty years of the Alzheimer's disease amyloid hypothesis: a genetic perspective. Cell 2005;120(4):545-555.

47. Roquemore EP, Banting G. Efficient trafficking of TGN38 from the endosome to the trans-Golgi network requires a free hydroxyl group at position 331 in the cytosolic domain. Mol Biol Cell 1998;9(8):2125-2144.

48. Pastorino L, Ikin AF, Nairn AC, Pursnani A, Buxbaum JD. The carboxyl-terminus of BACE contains a sorting signal that regulates BACE trafficking but not the formation of total A(beta). Mol Cell Neurosci 2002;19(2):175-185. 
49. Dutta D, Williamson CD, Cole NB, Donaldson JG. Pitstop 2 is a potent inhibitor of clathrin-independent endocytosis. PLoS One 2012;7(9):e45799.

50. Kelly BT, McCoy AJ, Spate K, Miller SE, Evans PR, Honing S, Owen DJ. A structural explanation for the binding of endocytic dileucine motifs by the AP2 complex. Nature 2008;456(7224):976-979.

51. Donaldson JG. Arfs, phosphoinositides and membrane traffic. Biochemical Society transactions 2005;33(Pt 6):1276-1278

52. van Ijzendoorn SC. Recycling endosomes. Journal of Cell Science 2006;119(Pt 9):1679-1681.

53. Lock JG, Stow JL. Rab11 in recycling endosomes regulates the sorting and basolateral transport of Ecadherin. Mol Biol Cell 2005;16(4):1744-1755.

54. Perret E, Lakkaraju A, Deborde S, Schreiner R, Rodriguez-Boulan E. Evolving endosomes: how many varieties and why? Current Opinion in Cell Biology 2005;17(4):423-434.

55. Grant BD, Donaldson JG. Pathways and mechanisms of endocytic recycling. Nat Rev Mol Cell Biol 2009;10(9):597-608.

56. Hsu VW, Bai M, Li J. Getting active: protein sorting in endocytic recycling. Nature reviews Molecular cell biology 2012;13(5):323-328.

57. Walter J, Fluhrer R, Hartung B, Willem M, Kaether C, Capell A, Lammich S, Multhaup G, Haass C. Phosphorylation regulates intracellular trafficking of beta-secretase. J Biol Chem 2001;276(18):1463414641.

58. Temkin P, Lauffer B, Jager S, Cimermancic P, Krogan NJ, von Zastrow M. SNX27 mediates retromer tubule entry and endosome-to-plasma membrane trafficking of signalling receptors. Nature Cell Biology 2011;13(6):715-721.

59. McKenzie JE, Raisley B, Zhou X, Naslavsky N, Taguchi T, Caplan S, Sheff D. Retromer guides STXB and CD8-M6PR from early to recycling endosomes, EHD1 guides $\mathrm{STxB}$ from recycling endosome to Golgi. Traffic 2012;13(8):1140-1159.

60. Andersen OM, Reiche J, Schmidt V, Gotthardt M, Spoelgen R, Behlke J, von Arnim CA, Breiderhoff T, Jansen P, Wu X, Bales KR, Cappai R, Masters CL, Gliemann J, Mufson EJ, et al. Neuronal sorting protein-related receptor sorLA/LR11 regulates processing of the amyloid precursor protein. Proc Natl Acad Sci U S A 2005;102(38):13461-13466.

61. Nielsen MS, Gustafsen C, Madsen P, Nyengaard JR, Hermey G, Bakke O, Mari M, Schu P, Pohlmann R, Dennes A, Petersen CM. Sorting by the cytoplasmic domain of the amyloid precursor protein binding receptor SorLA. Mol Cell Biol 2007;27(19):68426851.

62. Offe K, Dodson SE, Shoemaker JT, Fritz JJ, Gearing M, Levey AI, Lah JJ. The lipoprotein receptor LR11 regulates amyloid beta production and amyloid precursor protein traffic in endosomal compartments. J Neurosci 2006;26(5):1596-1603.

63. Gustafsen C, Glerup S, Pallesen LT, Olsen D, Andersen OM, Nykjaer A, Madsen P, Petersen CM. Sortilin and SorLA display distinct roles in processing and trafficking of amyloid precursor protein. The Journal of neuroscience : the official journal of the Society for Neuroscience 2013;33(1):64-71.

64. Kinoshita A, Fukumoto $\mathrm{H}$, Shah $\mathrm{T}$, Whelan $\mathrm{CM}$, Irizarry MC, Hyman BT. Demonstration by FRET of
BACE interaction with the amyloid precursor protein at the cell surface and in early endosomes. J Cell Sci 2003;116(Pt 16):3339-3346.

65. Small SA, Gandy S. Sorting through the cell biology of Alzheimer's disease: intracellular pathways to pathogenesis. Neuron 2006;52(1):15-31.

66. Huse JT, Liu K, Pijak DS, Carlin D, Lee VM, Doms RW. Beta-secretase processing in the trans-Golgi network preferentially generates truncated amyloid species that accumulate in Alzheimer's disease brain. J Biol Chem 2002;277(18):16278-16284.

67. Sullivan CP, Jay AG, Stack EC, Pakaluk M, Wadlinger E, Fine RE, Wells JM, Morin PJ. Retromer disruption promotes amyloidogenic APP processing. Neurobiology of disease 2011;43(2):338345 .

68. Zhang XM, Ellis S, Sriratana A, Mitchell CA, Rowe T. Sec15 is an effector for the Rab11 GTPase in mammalian cells. J Biol Chem 2004;279(41):4302743034.

69. Keller P, Toomre D, Diaz E, White J, Simons K. Multicolour imaging of post-Golgi sorting and trafficking in live cells. Nat Cell Biol 2001;3(2):140149.

70. Hunyady L, Baukal AJ, Gaborik Z, Olivares-Reyes JA, Bor M, Szaszak M, Lodge R, Catt KJ, Balla T. Differential PI 3-kinase dependence of early and late phases of recycling of the internalized AT1 angiotensin receptor. J Cell Biol 2002;157(7):12111222.

71. White AR, Du T, Laughton KM, Volitakis I, Sharples RA, Xilinas ME, Hoke DE, Holsinger RM, Evin G, Cherny RA, Hill AF, Barnham KJ, Li QX, Bush AI, Masters CL. Degradation of the Alzheimer disease amyloid beta-peptide by metal-dependent upregulation of metalloprotease activity. The Journal of biological chemistry 2006;281(26):17670-17680.

72. Ida N, Hartmann T, Pantel J, Schroder J, Zerfass R, Forstl H, Sandbrink R, Masters CL, Beyreuther K. Analysis of heterogeneous A4 peptides in human cerebrospinal fluid and blood by a newly developed sensitive Western blot assay. The Journal of biological chemistry 1996;271(37):22908-22914.

73. Kooy J, Toh BH, Pettitt JM, Erlich R, Gleeson PA. Human autoantibodies as reagents to conserved Golgi components - Characterization of a peripheral, 230-kDa compartment-specific Golgi protein. J Biol Chem 1992;267:20255-20263.

74. Lieu ZZ, Derby MC, Teasdale RD, Hart C, Gunn P, Gleeson PA. The Golgin, GCC88, Is Required for Efficient Retrograde Transport of Cargo from the Early Endosomes to the Trans-Golgi Network. Mol Biol Cell 2007;18:4979-4991.

75. Motley A, Bright NA, Seaman MN, Robinson MS. Clathrin-mediated endocytosis in AP-2-depleted cells. The Journal of cell biology 2003;162(5):909918.

76. Chesneau L, Dambournet D, Machicoane M, Kouranti I, Fukuda M, Goud B, Echard A. An ARF6/Rab35 GTPase cascade for endocytic recycling and successful cytokinesis. Current biology : CB 2012;22(2):147-153.

77. Schweitzer JK, D'Souza-Schorey C. A requirement for ARF6 during the completion of cytokinesis. Experimental Cell Research 2005;311(1):74-83.

78. Paing MM, Johnston CA, Siderovski DP, Trejo J. Clathrin adaptor AP2 regulates thrombin receptor 
constitutive internalization and endothelial cell resensitization. Molecular and cellular biology 2006;26(8):3231-3242.

79. Kjer-Nielsen L, van Vliet C, Erlich R, Toh BH, Gleeson PA. The Golgi-targeting sequence of the peripheral membrane protein p230. J Cell Sci 1999;112(Pt 11):1645-1654.

80. Woodcroft BJ, Hammond L, Stow JL, Hamilton NA. Automated organelle-based colocalization in wholecell imaging. Cytometry A 2009;75(11):941-950. 
Figure Legends

Figure 1. The steady state distribution of BACE1 in different cell types

$\mathrm{HeLa}, \mathrm{CHO}$ and neuronal SK-N-SH cells were transfected with BACE1 for $24 \mathrm{~h}$. Monolayers were fixed, permeabilised and stained with polyclonal BACE1 antibodies (red) and monoclonal antibodies to (A) GM130 (green) or (B) Rab11 (green). (C) HeLa cells, transfected with BACE1 as above were stained with mouse monoclonal antibodies to golgin-97 (TGN marker), Rab11 or EEA1 and the percentages of BACE1 pixels that overlapped with each marker were determined using the plugin OBCOL on the ImageJ program. Data is expressed as the mean $+/-$ SEM $(n=15)$. Stars indicate location of the nucleus. Bars represent $10 \mu \mathrm{m}$ except for magnified images where bars represents $5 \mu \mathrm{m}$ except for magnified images where bars represent $10 \mu \mathrm{m}$.

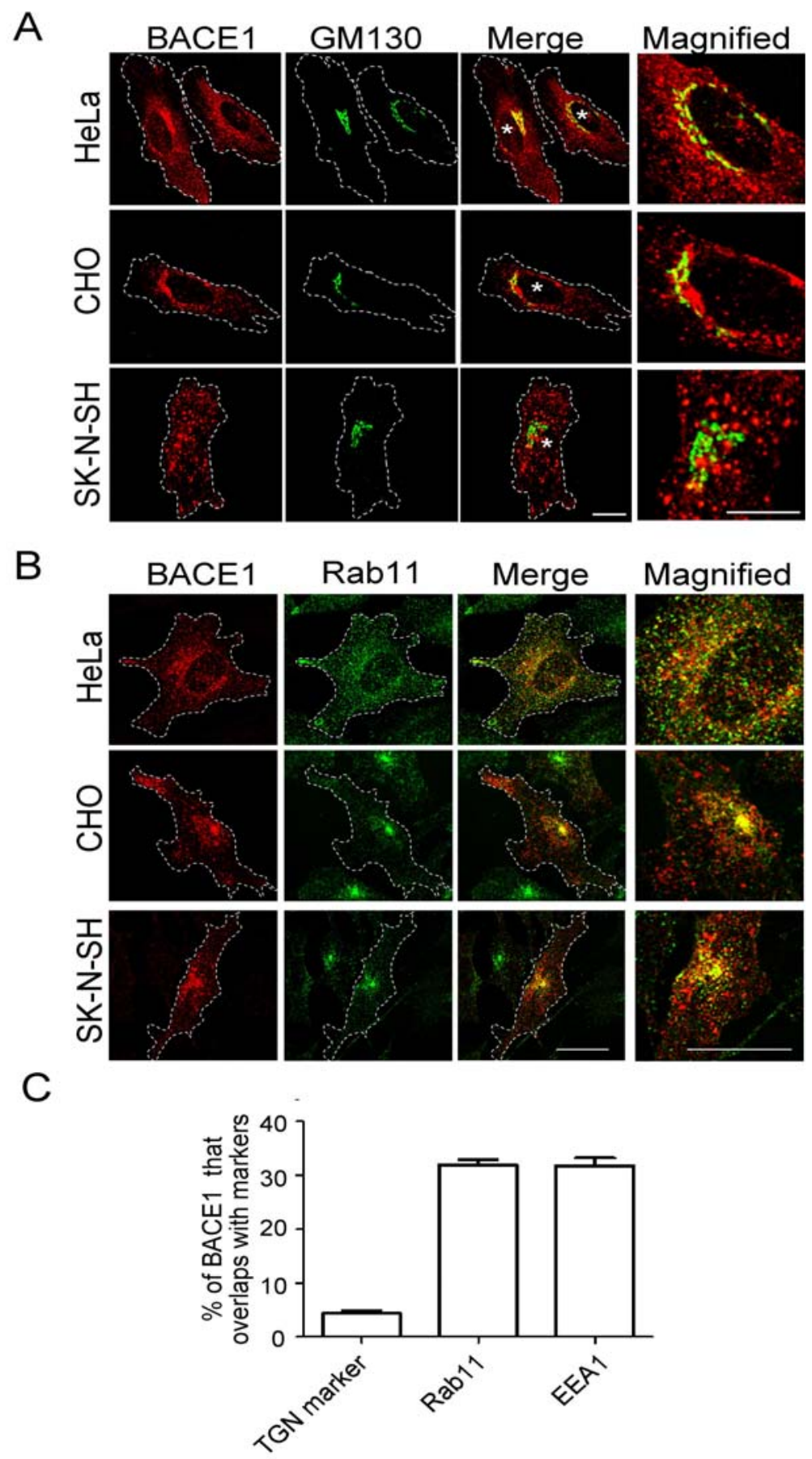

This article is protected by copyright. All rights reserved. 
Figure 2. Internalised BACE1 transits the juxtanuclear recycling endosomes

(A) HeLa cells were transfected with BACE1 for $24 \mathrm{~h}$ and monolayers incubated with polyclonal BACE1 antibodies for 30 min on ice. Cells were washed in PBS and incubated in serum-free media for up to $60 \mathrm{~min}$ at $37^{\circ} \mathrm{C}$, then fixed, permeabilised and stained for internalised antibody-BACE1 complexes with Alexa568-conjugated anti-rabbit IgG (red) and monoclonal golgin-97 antibodies (green). (B) HeLa cells were transfected with BACE1 for $24 \mathrm{~h}$ prior to the antibody internalisation assay, followed by staining with Alexa568-conjugated anti-rabbit IgG (red) and EEA1 antibodies (green). (C) HeLa cells were transfected with BACE1 for $24 \mathrm{~h}$ prior to the antibody internalisation assay, followed by staining with Alexa568conjugated anti-rabbit IgG (red) and endogenous Rab11 (green). (D) The internalisation assay was carried out by incubating cells with both polyclonal BACE1 antibody and 568-conjugated transferrin (red), followed by staining with Alexa488conjugated anti-rabbit IgG (green). The percentage of BACE1 at either (E) recycling endosomes or (F) the TGN was determined by calculating the percentage of total BACE1 pixels that overlapped with Rab11 or golgin-97 respectively using the plugin OBCOL on ImageJ program. (G) The percentage of total BACE1 pixels which overlapped with internalised 568Tf. Data is expressed as the mean $+/$ - SEM ( $\mathrm{n}=20$ for each time-point). Bars represent $10 \mu \mathrm{m}$, except for magnified images where bar represents $5 \mu \mathrm{m}$. In B the boxed region of the merge is magnified on the RHS.
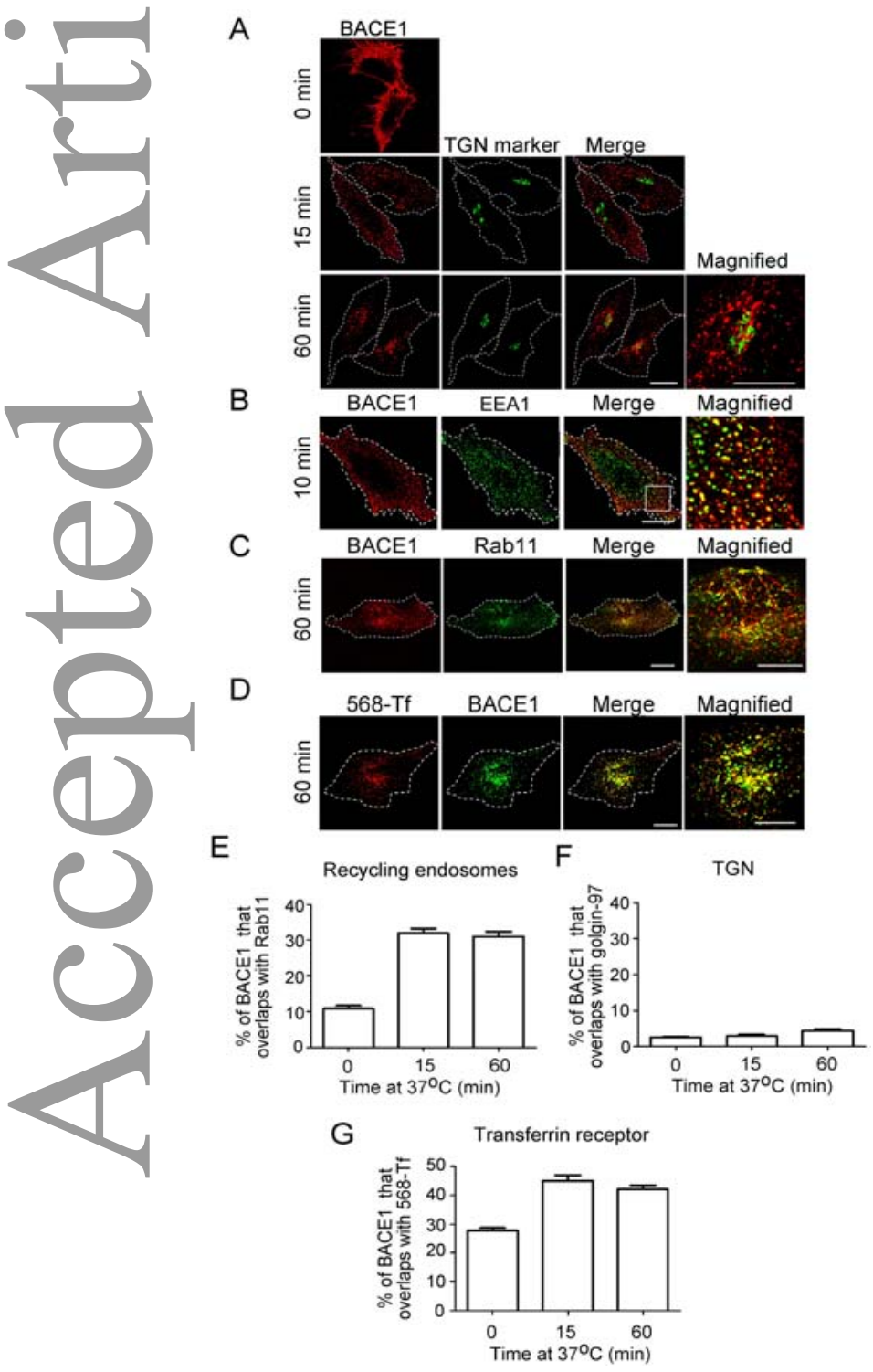

This article is protected by copyright. All rights reserved. 
Figure 3. Cell surface BACE1 is internalised via clathrin-mediated endocytosis

HeLa cells were transfected with either control siRNA, CHC17(1) siRNA, $\mu 2(1) \operatorname{siRNA}$, AP2 $\alpha \quad$ aptin(1) siRNA or Arf6(1) siRNA for $48 \mathrm{~h}$ and transfected again with BACE1 for a further $24 \mathrm{~h}$. (A) For immunoblotting, cells were lysed in SDS-PAGE reducing buffer and cell extracts were subjected to SDS-PAGE on 4-12\% gradient polyacrylamide gel. Proteins were transferred to a PVDF membrane and probed with mouse anti- $\alpha$ tubulin antibody and mouse anti-CHC antibody, rabbit anti- $\mu 2$ antibody, mouse anti- $\alpha$ adaptin antibody or mouse anti-Arf6 antibody, using a chemiluminescence detection system. (B) For internalisation assays, cells were incubated with rabbit anti-BACE1 antibody and mouse anti-TfR antibody (OKT9) on ice for $30 \mathrm{~min}$. Cells were then washed with cold PBS and incubated in serum-free media at $37^{\circ} \mathrm{C}$ for $15 \mathrm{~min}$, and then fixed and permeabilised. Monolayers were then stained for antibody-bound BACE1 and antibody-bound TfR with Alexa568 conjugated anti-rabbit IgG (grey) and Alexa488 conjugated anti-mouse IgG respectively (grey). (C) HeLa cells were transfected with either BACE1 or BACE1LL/AA for $24 \mathrm{~h}$. Monolayers were first lifted by trypsin digest at $37^{\circ} \mathrm{C}$ for $3 \mathrm{~min}$. Cells were washed with PBS and incubated with rabbit anti-BACE1 antibody for $30 \mathrm{~min}$ on ice. Cells for the 0 min timepoint were fixed immediately, whereas cells for internalisation were incubated in warm serum-free media for 10 min at $37^{\circ} \mathrm{C}$, and then fixed. Cells were quenched in $50 \mathrm{mM} \mathrm{NH}_{4} \mathrm{Cl}$ and blocked in $5 \% \mathrm{FCS} / \mathrm{PBS}$, without permeabilisation, and then resuspended in flow cytometry buffer and stained for cell surface BACE1 with Alexa568-conjugated IgG. 20,000 events were collected per sample and percentage of Alexa568-positive events indicated. Untransfected cells were incubated with primary and secondary antibodies to determine the gating, as indicated in the upper panel. Bar represents $10 \mu \mathrm{m}$. 
A

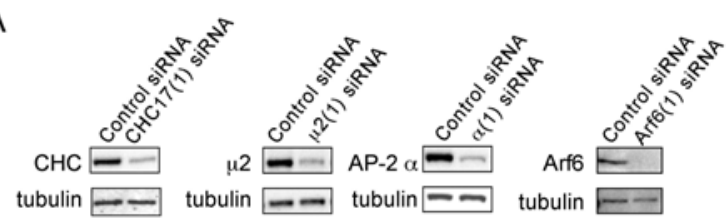

B

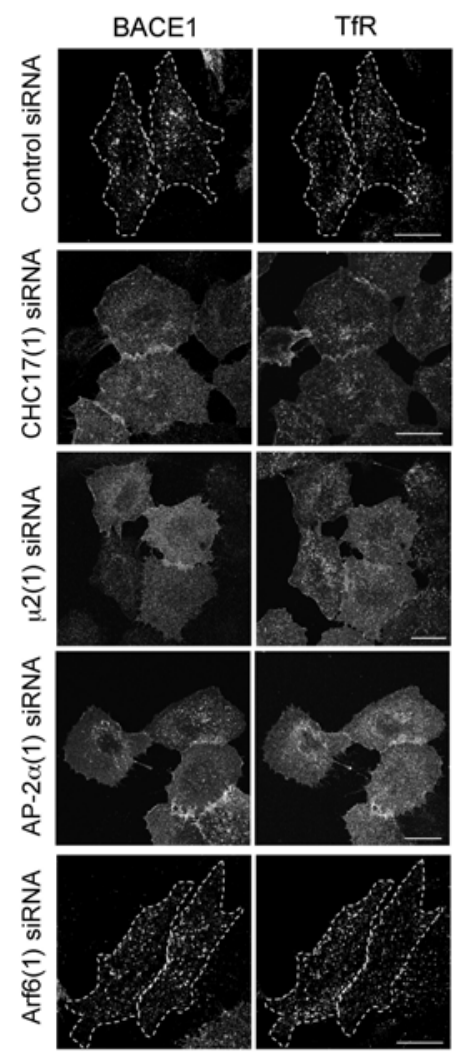

C
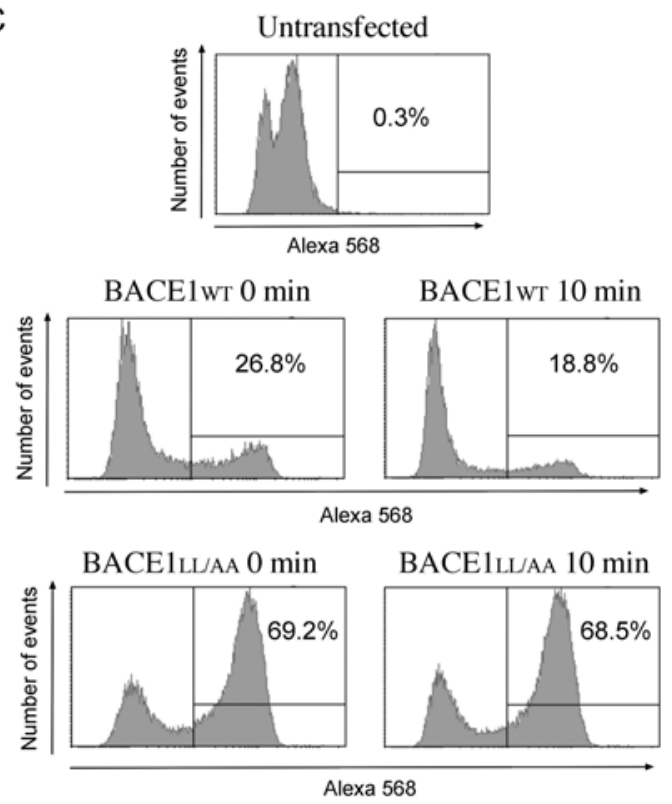

This article is protected by copyright. All rights reserved. 
Figure 4. Reversible inhibition of clathrin-mediated internalisation of BACE1

(A) Cartoon depicting cell surface biotinylation of BACE1 and release of the biotin tag with GSH cleavage buffer. (B) HeLa cells were transfected with BACE1 for $24 \mathrm{~h}$ and cell surface biotinylation was carried out at $4^{\circ} \mathrm{C}$. Biotinylated cells were either analysed directly $(0 \mathrm{~min}-\mathrm{GSH})$, or subjected to glutathione $(\mathrm{GSH})$ cleavage at $4^{\circ} \mathrm{C}(0 \mathrm{~min}+\mathrm{GSH})$; incubated in warm serum-free media at $37^{\circ} \mathrm{C}$ for $30 \mathrm{~min}$, followed by cleavage $(30 \mathrm{~min}+\mathrm{GSH})$; or incubated in serum-free media at $37^{\circ} \mathrm{C}$ for 60 $\mathrm{min}$, with cleavage at both the $30 \mathrm{~min}$ and $60 \mathrm{~min}$ intervals $(60 \mathrm{~min}+\mathrm{GSH})$. Cells were lysed and extracts were incubated with NeutrAvidin-agarose. Bound proteins were subjected to SDS-PAGE on a $10 \%$ polyacrylamide gel. Proteins were transferred to a PVDF membrane and probed with rabbit anti-BACE1 antibody using a chemiluminescence detection system. (C) Cell surface biotinylation and pitstop 2 treatment. Cell surface biotinylation was carried out on BACE1-transfected cells as described above. Cells were then incubated for 15 min with $30 \mu \mathrm{M}$ pitstop 2 at $4^{\circ} \mathrm{C}$ and either incubated in serum-free media at $37^{\circ} \mathrm{C}$ for $30 \mathrm{~min}$, followed by glutathione cleavage or subjected to a washout in cold C-DMEM on ice for $1 \mathrm{~h}$, followed by internalisation at $37^{\circ} \mathrm{C}$ for $30 \mathrm{~min}$ and glutathione cleavage. Cells were lysed and processed as for B. (D) Bar graph of intensity of biotin bands after cell surface biotinylation and pitstop 2 treatment. Densitometric quantitation of bands was performed on 2 independent experiments using ImageJ. Values are represented as mean \pm standard error. (E) HeLa cells were transfected with BACE1 for $24 \mathrm{~h}$ and monolayers were incubated with rabbit anti-BACE1 antibody for $30 \mathrm{~min}$ on ice. Cells were fixed or treated with $30 \mu \mathrm{M}$ pitstop 2 for $15 \mathrm{~min}$ on ice. Pitstop 2-treated cells were subjected to internalisation at $37^{\circ} \mathrm{C}$ in serum-free media for $30 \mathrm{~min}$, with or without a 1-hour washout in cold C-DMEM. Cells were fixed and permeabilised, followed by staining with Alexa568-conjugated anti-rabbit IgG. In the magnified image of the pitstop/washout sample, cells were stained with Alexa568-conjugated anti-rabbit IgG (red) and mouse anti-EEA1 antibodies (green). Data is from two independent experiments. Bars represents $10 \mu \mathrm{m}$. 
A
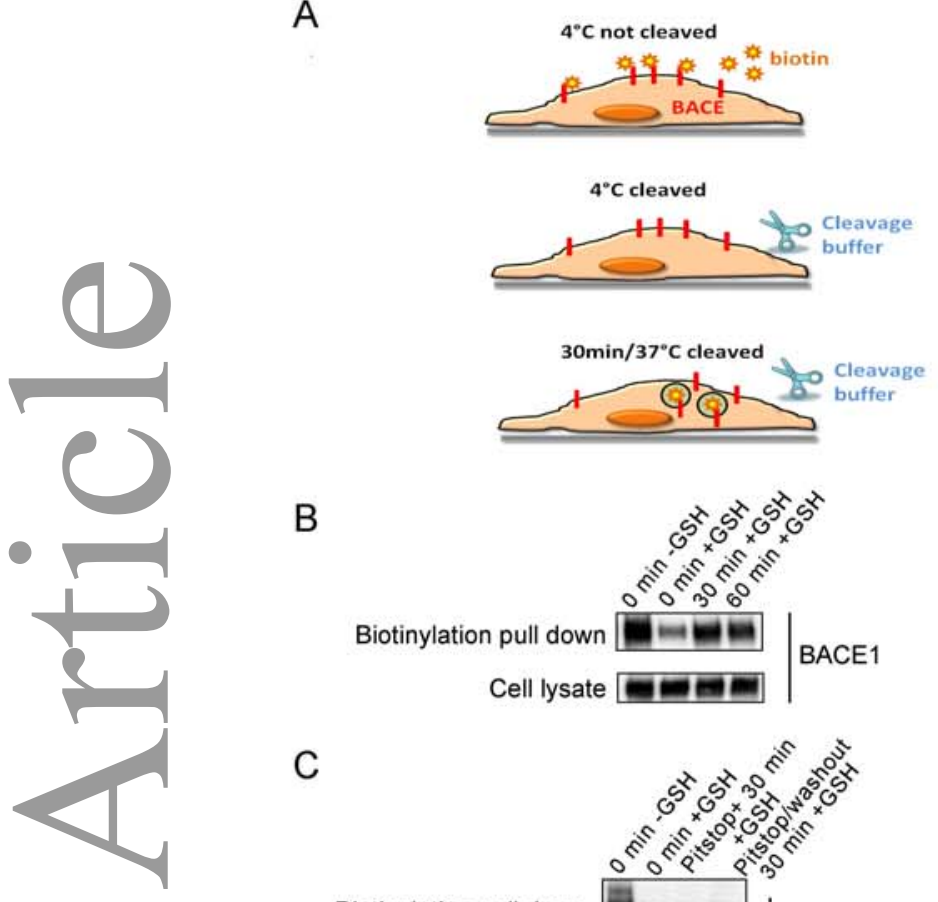

B

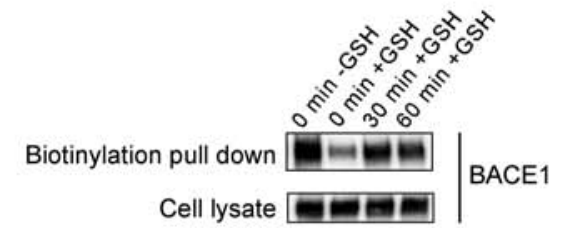

C

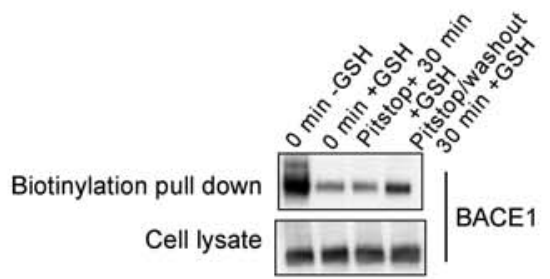

D

Inhibition of BACE1 internalisation by pitstop 2
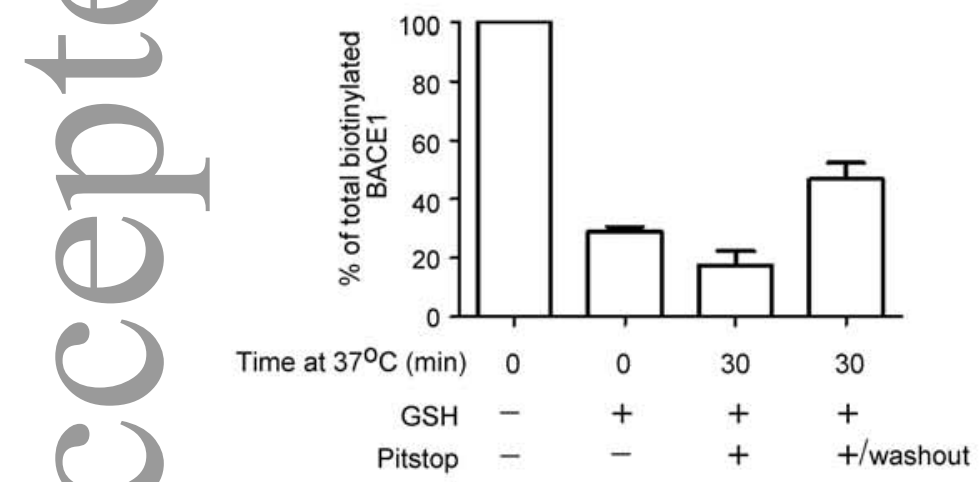

E

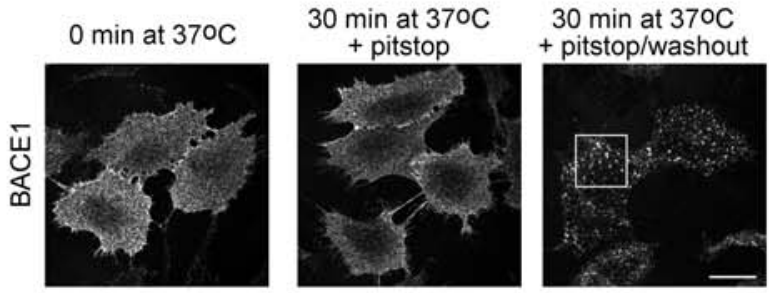

Magnified

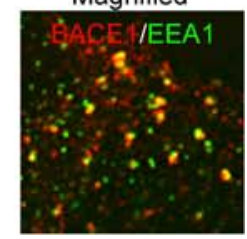

This article is protected by copyright. All rights reserved. 
Figure 5. The steady state distribution of BACE/TGN38 in HeLa cells

(A) Schematic of BACE1 and BACE/TGN38 constructs. (B) HeLa cells were transfected with BACE/TGN38 for $24 \mathrm{~h}$ and fixed, quenched and permeabilised, followed by staining with polyclonal BACE1 antibodies (red) and monoclonal GM130 antibodies (green). (C) HeLa cells were transfected with BACE/TGN38 for $24 \mathrm{~h}$ and monolayers were incubated with polyclonal BACE1 antibodies for $30 \mathrm{~min}$ on ice. Cells were washed in PBS and incubated in serum-free media for up to 60 min at $37^{\circ} \mathrm{C}$, then fixed, permeabilised and stained for internalised antibody-BACE1 complexes with Alexa568-conjugated anti-rabbit IgG (red) and monoclonal GM130 antibodies (green) as the Golgi marker. (D) The proportion of BACE/TGN38 at the Golgi was determined by calculating the percentage of total BACE1 pixels that overlapped with GM130, using the plugin OBCOL on ImageJ. Data is expressed as the mean $+/-$ SEM ( $\mathrm{n}=20$ for each time-point). Bars represent $10 \mu \mathrm{m}$ and 5 $\mu \mathrm{m}$ (magnified images).
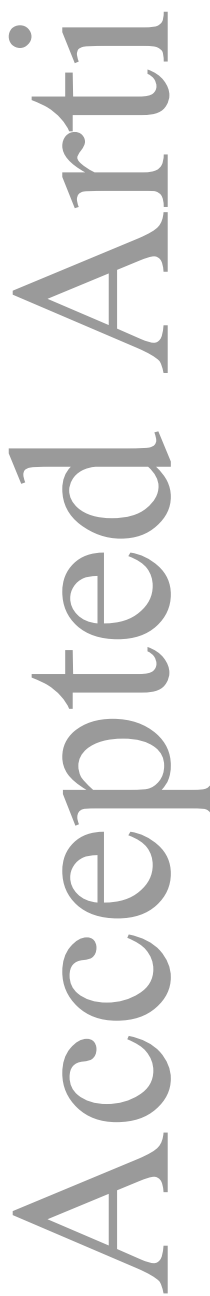


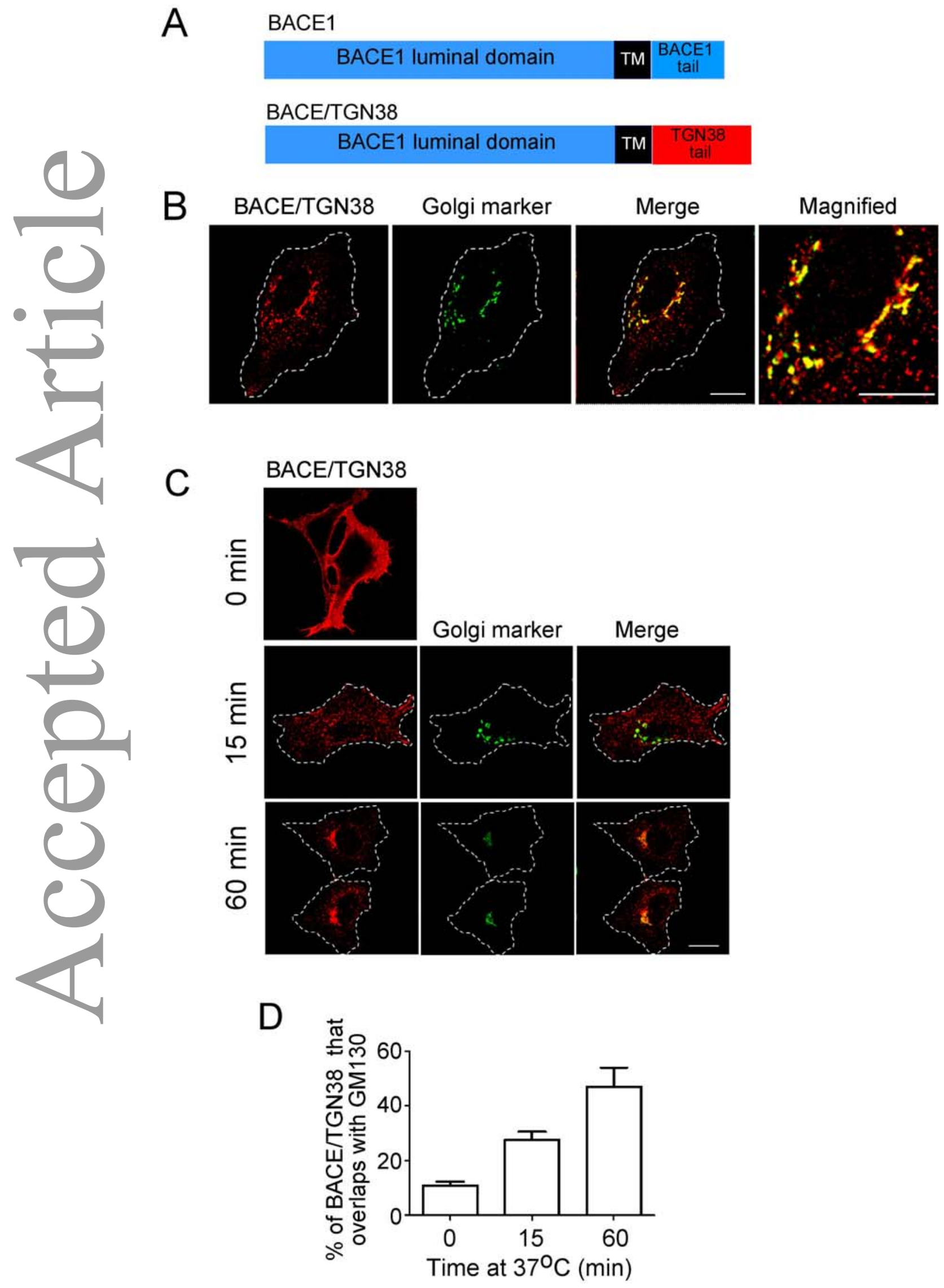

This article is protected by copyright. All rights reserved. 
Figure 6. Internalised APP is transported to the late endosome and not the recycling endosomes

HeLa cells were transfected with APP and either (A) GFP-Rab11wt, (B) Cherry-FYVE or (C) GFP-Rab7(Q67L) for $24 \mathrm{~h}$ and monolayers incubated with monoclonal mouse APP antibodies for $30 \mathrm{~min}$ on ice. Cells were washed in PBS and incubated in serum-free media for up to $90 \mathrm{~min}$ at $37^{\circ} \mathrm{C}$, then fixed, permeabilised and stained for internalised antibody-APP complexes with (A,C) Alexa568-conjugated anti-mouse IgG (red) or (B) Alexa488 conjugated anti-mouse IgG. The proportion of internalised APP at (D) early endosomes, (E) late endosomes, (F) recycling endosomes and (G) the TGN was determined by calculating the percentage of total internalised APP pixels that overlapped with EEA1, GFP-Rab7(Q67L), GFP-Rab11wt or p230 respectively, using the plugin OBCOL on ImageJ. Data is expressed as the mean $+/-$ SEM ( $\mathrm{n}=20$ for each time-point). Bars represent $10 \mu \mathrm{m}$ except for magnified images of $\mathrm{B}$ and $\mathrm{C}$ where bar represents $5 \mu \mathrm{m}$.
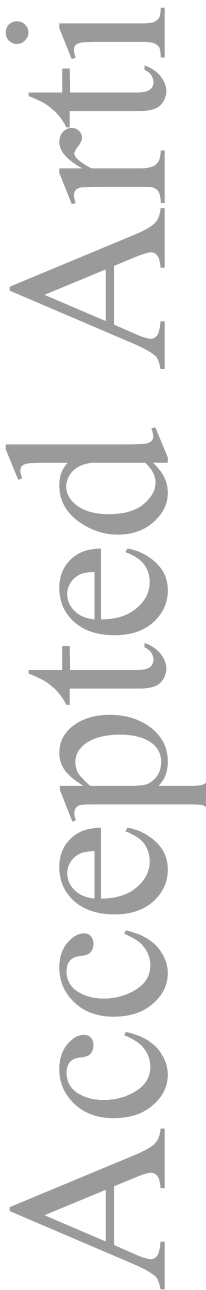


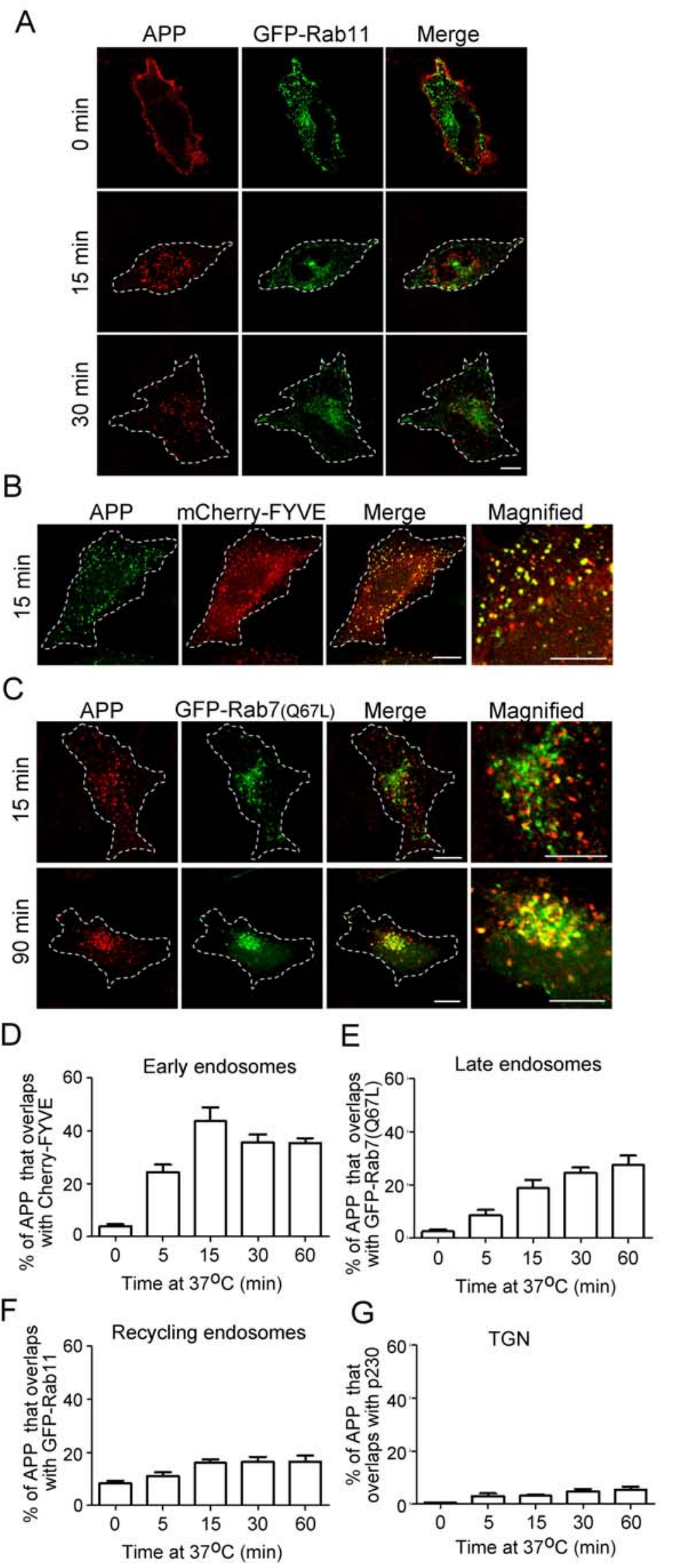

This article is protected by copyright. All rights reserved. 
Figure 7. BACE1 internalisation in BACE1 and BACE/TGN38 CHO-APP stable cell lines

(A) Steady state distribution of BACE1 constructs in stable CHO APP cell lines. Stably-expressing CHO APP BACE1 or CHO APP BACE/TGN38 cells were fixed, quenched and permeabilised, followed by staining with BACE1 polyclonal antibodies (red), monoclonal GM130 antibodies (green) and DAPI (blue). (B) For BACE1 internalisation, CHO APP BACE1 or BACE/TGN38 cells were incubated with polyclonal BACE1 antibody in serum-free media at $37^{\circ} \mathrm{C}$ for $2 \mathrm{~h}$. Monolayers were fixed, quenched and permeabilised, followed by staining with Alexa568-conjugated anti-rabbit IgG (red), monoclonal GM130 antibodies (green) and DAPI (blue). (C) The proportion of internalised antibody-BACE1 or antibodyBACE/TGN38 at the Golgi was determined by calculating the percentage of total BACE1 pixels that overlapped with GM130, using the plugin OBCOL on ImageJ program. Data is expressed as the mean $+/$ - SEM ( $n=20$ for each time-point). Bars represent $10 \mu \mathrm{m} . * * *$ indicates $p<0.001$.
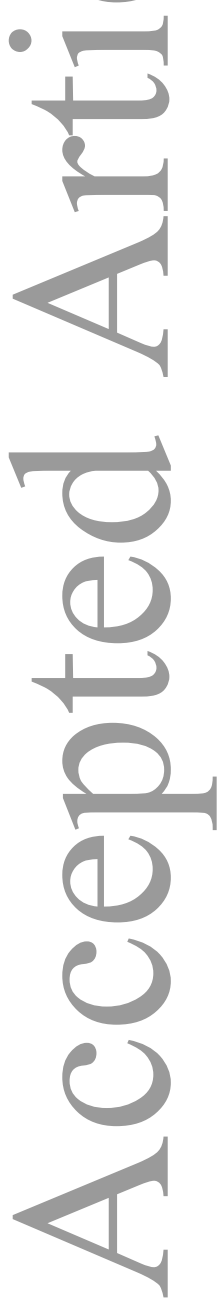
A
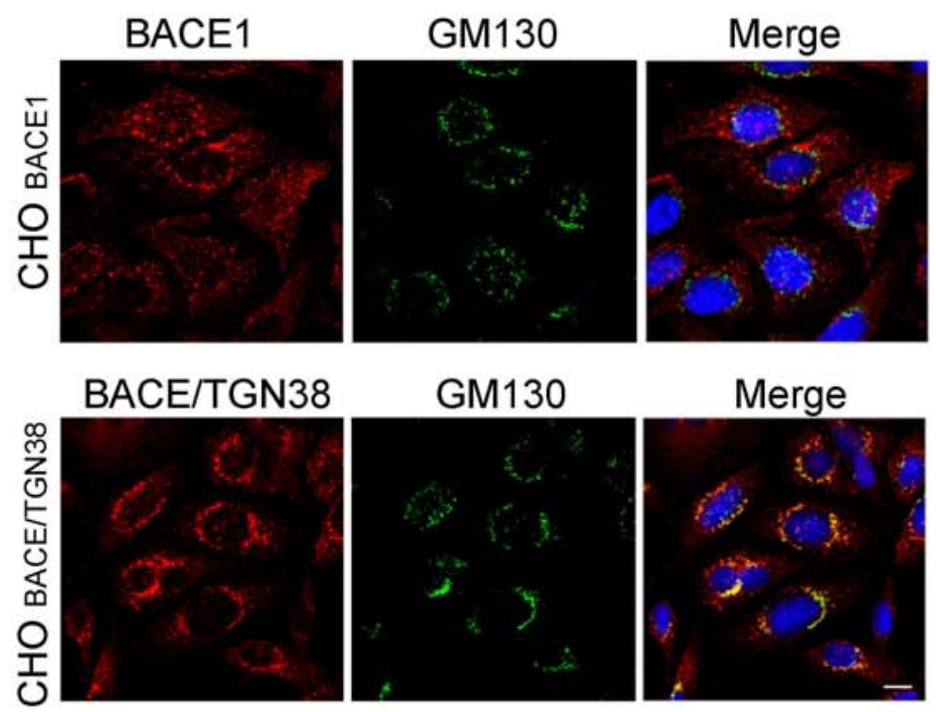

B

Continuous $2 \mathrm{~h}$ BACE1 $\mathrm{Ab}$ internalisation in stable $\mathrm{CHO}$ cell lines
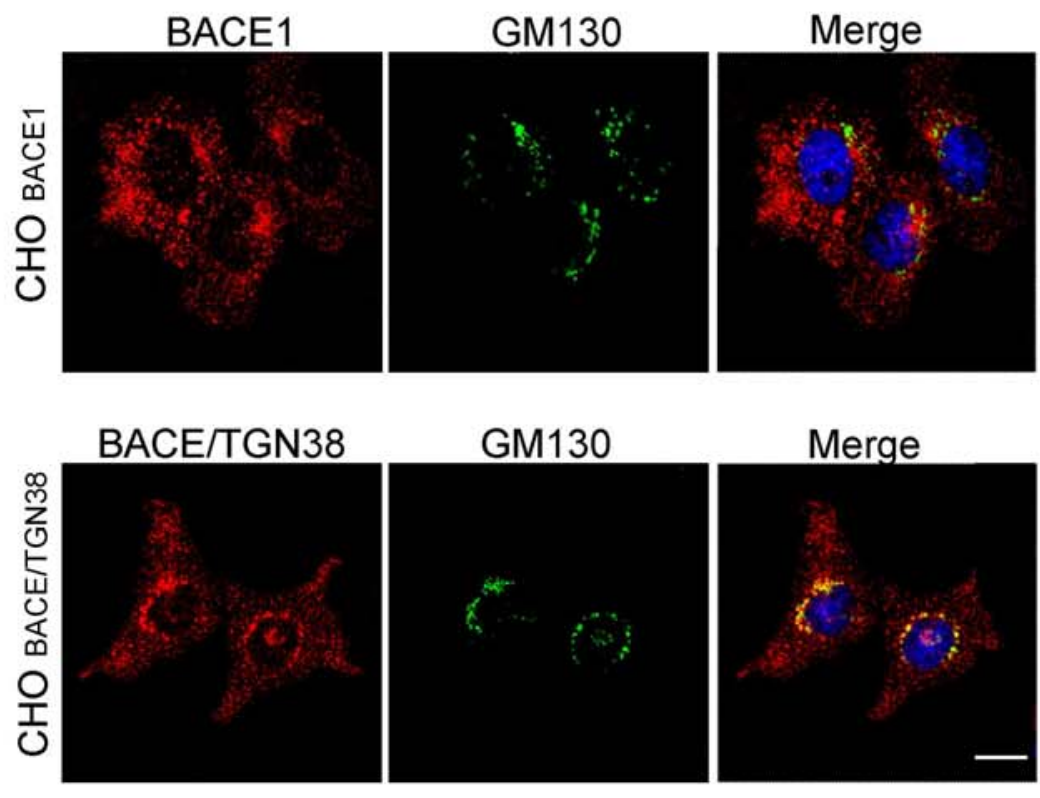

C

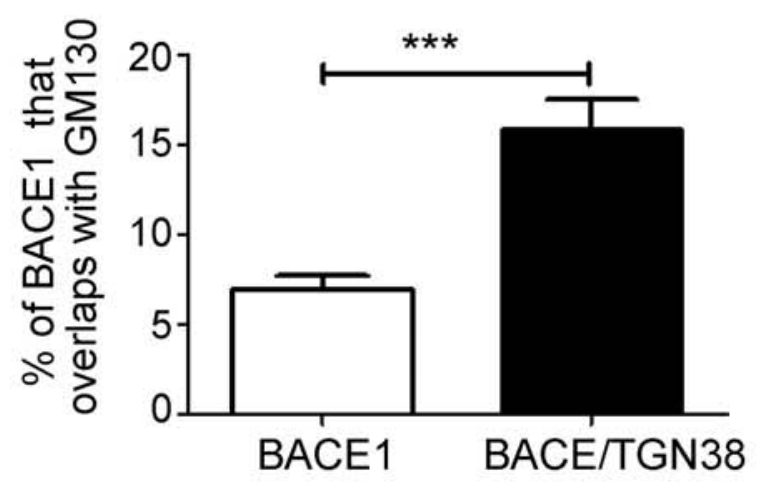

This article is protected by copyright. All rights reserved. 
Figure 8. AB levels from CHO APP BACE1 and BACE/TGN38 stable cell lines

(A) CHO-APP BACE1 or CHO-APP BACE/TGN38 cell lines were subjected to SDS-PAGE, transferred onto membrane and probed were probed with polyclonal BACE1 antibody to determine levels of BACE1 or BACE/TGN38. The membrane then stripped and reprobed with mouse anti- $\alpha$-tubulin antibodies (B) Conditioned media from stably-expressing CHO-APP BACE1 or CHO-APP BACE/TGN38 cell lines were subjected to SDS-PAGE, transferred onto membrane and probed with mouse W02 antibody to detect $\operatorname{sAPP} \alpha$ and A $\beta$ bands. (C) Bar graph of the intensity of A $\beta$ bands from four replicates. The levels of A $\beta$ in these experiments were normalised for the level of BACE protein in each experiment. Densitometry of bands was carried out using Image J. * indicates $p<0.05$.
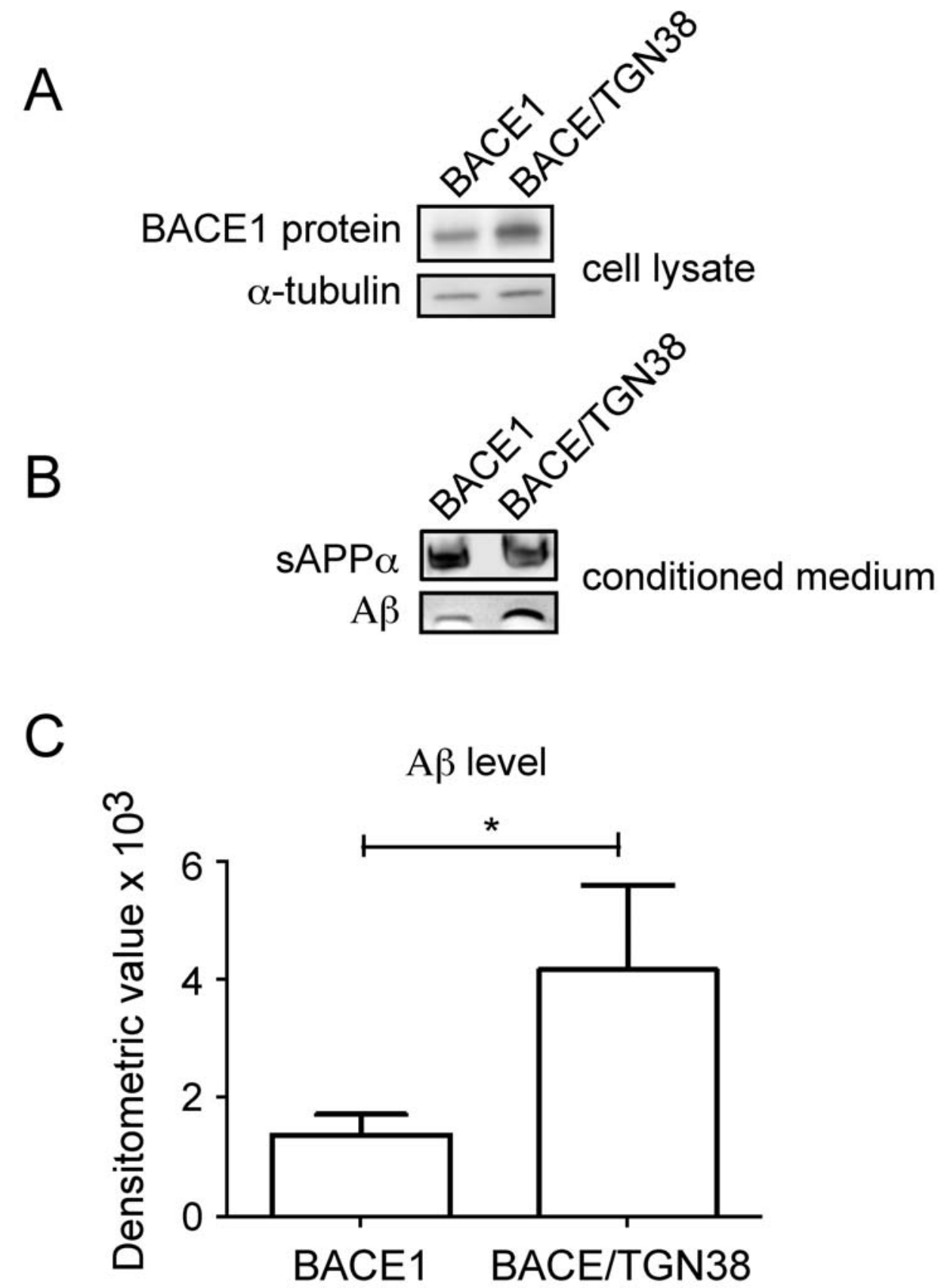

This article is protected by copyright. All rights reserved. 
Figure 9.

Model of trafficking itineraries of BACE1 and APP

(Left) Newly-synthesized BACE1 and APP are transported from the TGN to the PM. (Right) The pathways of internalised BACE1 and APP diverge at the early endosomes. Our data suggests that BACE1 is transported from the early endosome to the recycling endosomes, not the TGN, for return to the PM. On the other hand the bulk of APP is retained in the maturing early endosome for delivery to the late endosomes/lysosomes.

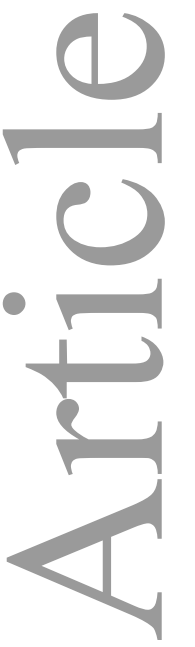

\section{Anterograde pathways}
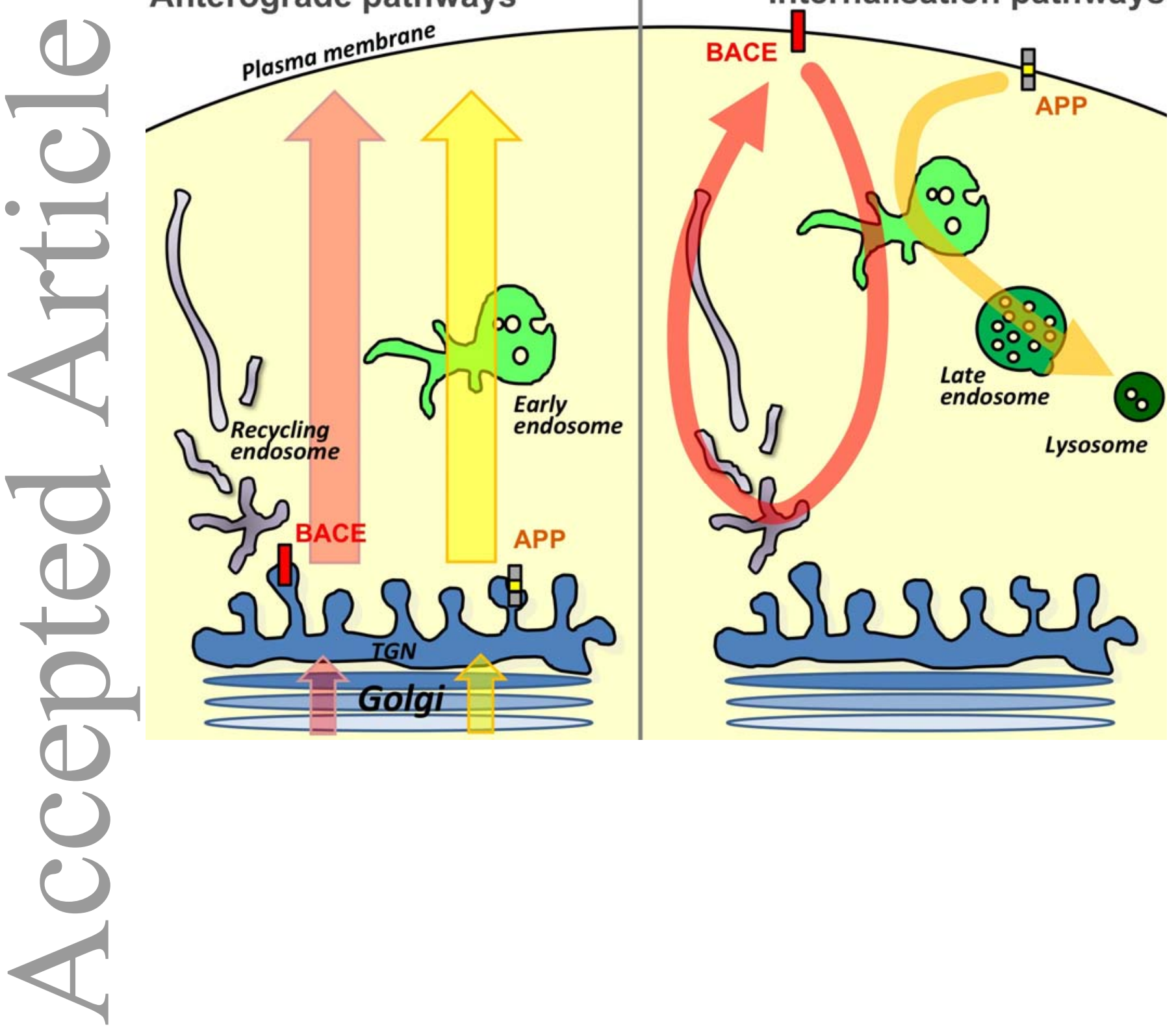

This article is protected by copyright. All rights reserved. 
Table 1. Analysis of Internalisation of surface BACE1 by flow cytometry

HeLa cells were transfected with siRNAs for $48 \mathrm{~h}$ and transfected again with BACE1 for a further $24 \mathrm{~h}$. Cell suspensions were incubated with rabbit anti-BACE1 antibody for 30 min on ice. Cells were fixed immediately or incubated in warm serum-free media for 10 min at $37^{\circ} \mathrm{C}$. Cells were quenched and stained for cell surface BACE1 with Alexa568conjugated IgG and analysed by flow cytometry. 20,000 events were collected per sample and levels of surface staining at $0 \mathrm{~min}$ and $10 \mathrm{~min}$ compared. Data presented for each treatment is the mean +/- SD from 3-4 experiments using two independent siRNA for each target.

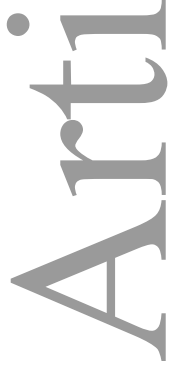

\begin{tabular}{ccc}
\hline Treatment & \% Knockdown & $\begin{array}{c}\text { \% Reduction of BACE1- } \\
\text { positive cells after 10 min } \\
\text { internalisation }\end{array}$ \\
\hline control siRNA & NA & $30.73 \pm 5.94$ \\
CHC17 siRNA & 80 & $11.58 \pm 6.46$ \\
$\boldsymbol{\mu} 2$ siRNA & 75 & $10.58 \pm 6.00$ \\
$\boldsymbol{\alpha}$-adaptin siRNA & 85 & $12.15 \pm 4.47$ \\
Arf6 siRNA & 95 & $25.32 \pm 6.37$ \\
\hline
\end{tabular}

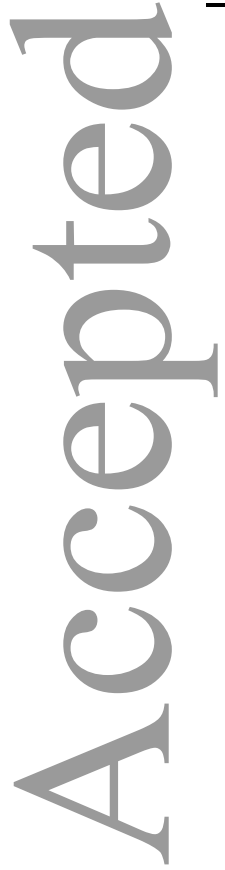

This article is protected by copyright. All rights reserved. 


\section{Supplementary Figures}

Figure S1 The steady state distribution of BACE1 in HeLa cells

HeLa cells were transfected with BACE1 for $24 \mathrm{~h}$. Monolayers were fixed, permeabilised and stained with polyclonal BACE1 antibodies (red) and monoclonal antibodies to EEA1 (green) or CD63 (green), as indicated. Bar represents $10 \mu \mathrm{m}$

\section{Figure S2 Overexpression of Rab11S25 alters the transport of internalised BACE1}

(A) HeLa cells were transfected with BACE1 together with either Rab11wt or Rab11S25N for $24 \mathrm{~h}$ and monolayers incubated with polyclonal BACE1 antibodies for $30 \mathrm{~min}$ on ice. Cells were washed in PBS and incubated in serum-free media for up to $90 \mathrm{~min}$ at $37^{\circ} \mathrm{C}$, then fixed, permeabilised and stained for internalised antibody-BACE1 complexes with Alexa568-conjugated anti-rabbit IgG (red) and EEA1 antibodies (green). The percentage of BACE1 at the early endosome was determined by calculating the percentage of total BACE1 pixels that overlapped with EEA1 using the plugin OBCOL on ImageJ program. Data is expressed as the mean $+/$ SEM ( $\mathrm{n}=12-15$ for each time-point). ${ }^{* *}$ indicates $p<0.01$.

\section{Figure S3 Simultaneous trafficking of Internalised BACE1 and TGN38}

(A) HeLa cells were co-transfected with BACE1 and TGN38-CFP for $24 \mathrm{~h}$ and transfected monolayers incubated with polyclonal rabbit anti-BACE1 antibodies and mouse anti-TGN38 antibodies for $30 \mathrm{~min}$ on ice. Cells were washed in PBS and incubated in serum-free media for up to $60 \mathrm{~min}$ at $37^{\circ} \mathrm{C}$, then fixed, permeabilised and stained for internalised antibodyBACE1 complexes with Alexa568-conjugated anti-rabbit IgG (red) and for internalised antibody-TGN38-CFP complexes with Alexa488-conjugated anti-mouse IgG (green). The steady state localisation of TGN38-CFP was used as a marker of the TGN. In the top panel the boxed region of the merge is magnified on the RHS. Bars represent $10 \mu \mathrm{m}$

\section{Figure S4 Internalised CD8/APP is delivered to the late endosomes/lysosomes.}

HeLa cells were transfected with (A) CD8/APP and GFP-Rab7(Q67L) or (B,C) CD8/APP alone for 24 h. Monolayers were incubated with mouse anti-CD8 antibodies on ice for $30 \mathrm{~min}$, washed with cold PBS and incubated in serum-free media at $37^{\circ} \mathrm{C}$ for up to $180 \mathrm{~min}$. Cells were stained with Alexa568-conjugated anti-mouse IgG and (B) rabbit anti-LAMP1 antibodies (green) and (C) human p230 antibodies (green). The percentage of CD8/APP pixels that overlapped with (D) GFP-Rab7, (E) LAMP1 or (F) p230 was determined using the plugin OBCOL on ImageJ. Data is expressed as the mean $+/-$ SEM $(n=15)$. Bars represent $10 \mu \mathrm{m}$ and in magnified images, bars represent $5 \mu \mathrm{m}$. 